OPEN ACCESS

Edited by:

Francisco Javier Corpas,

Spanish National Research Council,

Spain

Reviewed by:

Raimund Tenhaken,

University of Salzburg, Austria Alberto A. Iglesias,

National University of the Littoral,

Argentina

*Correspondence:

Christian Lindermayr

lindermayr@helmholtz-muenchen.de

tThese authors have contributed equally to this work.

Specialty section:

This article was submitted to

Plant Physiology,

a section of the journal

Frontiers in Plant Science

Received: 27 July 2016

Accepted: 24 October 2016

Published: 10 November 2016

Citation:

Kovacs I, Holzmeister C, Wirtz M, Geerlof A, Fröhlich T, Römling G, Kuruthukulangarakoola GT, Linster E,

Hell R, Arnold GJ, Durner J and Lindermayr C (2016) ROS-Mediated

Inhibition of S-nitrosoglutathione

Reductase Contributes to the

Activation of Anti-oxidative

Mechanisms.

Front. Plant Sci. 7:1669.

doi: $10.3389 / \mathrm{fp} / \mathrm{s} .2016 .01669$

\section{ROS-Mediated Inhibition of S-nitrosoglutathione Reductase Contributes to the Activation of Anti-oxidative Mechanisms}

\author{
Izabella Kovacs ${ }^{1 \dagger}$, Christian Holzmeister ${ }^{1 \dagger}$, Markus Wirtz ${ }^{2}$, Arie Geerlof ${ }^{3}$, \\ Thomas Fröhlich", Gaby Römling ${ }^{1}$, Gitto T. Kuruthukulangarakoola'1, Eric Linster ${ }^{2}$, \\ Rüdiger Hell2, Georg J. Arnold ${ }^{4}$, Jörg Durner ${ }^{1,5}$ and Christian Lindermayr ${ }^{1 *}$
}

\footnotetext{
${ }^{1}$ Institute of Biochemical Plant Pathology, Helmholtz Zentrum München - German Research Center for Environmental Health, Neuherberg, Germany, ${ }^{2}$ Centre for Organismal Studies Heidelberg, Ruprecht-Karls-Universität Heidelberg, Heidelberg, Germany, ${ }^{3}$ Institute of Structural Biology, Helmholtz Zentrum München - German Research Center for Environmental Health, Neuherberg, Germany, ${ }^{4}$ Laboratory for Functional Genome Analysis, Gene Center,

Ludwig-Maximilians-Universität München, Munich, Germany, ${ }^{5}$ Lehrstuhl für Biochemische Pflanzenpathologie, Technische Universität München, Freising, Germany
}

Nitric oxide (NO) has emerged as a signaling molecule in plants being involved in diverse physiological processes like germination, root growth, stomata closing and response to biotic and abiotic stress. S-nitrosoglutathione (GSNO) as a biological $\mathrm{NO}$ donor has a very important function in NO signaling since it can transfer its NO moiety to other proteins (trans-nitrosylation). Such trans-nitrosylation reactions are equilibrium reactions and depend on GSNO level. The breakdown of GSNO and thus the level of S-nitrosylated proteins are regulated by GSNO-reductase (GSNOR). In this way, this enzyme controls $S$-nitrosothiol levels and regulates NO signaling. Here we report that Arabidopsis thaliana GSNOR activity is reversibly inhibited by $\mathrm{H}_{2} \mathrm{O}_{2}$ in vitro and by paraquat-induced oxidative stress in vivo. Light scattering analyses of reduced and oxidized recombinant GSNOR demonstrated that GSNOR proteins form dimers under both reducing and oxidizing conditions. Moreover, mass spectrometric analyses revealed that $\mathrm{H}_{2} \mathrm{O}_{2}$-treatment increased the amount of oxidative modifications on $\mathrm{Zn}^{2+}$-coordinating Cys47 and Cys177. Inhibition of GSNOR results in enhanced levels of $S$-nitrosothiols followed by accumulation of glutathione. Moreover, transcript levels of redox-regulated genes and activities of glutathione-dependent enzymes are increased in gsnor-ko plants, which may contribute to the enhanced resistance against oxidative stress. In sum, our results demonstrate that reactive oxygen species (ROS)dependent inhibition of GSNOR is playing an important role in activation of anti-oxidative mechanisms to damping oxidative damage and imply a direct crosstalk between ROSand NO-signaling.

Keywords: nitric oxide, S-nitrosoglutathione reductase, S-nitrosothiols, reactive oxygen species, oxidative stress, hydrogen peroxide, paraquat, Arabidopsis thaliana 


\section{INTRODUCTION}

Plants are continuously facing to the changing environment that affects plant growth and productivity. To deal with multiple stress conditions, plants have developed adaptive responses. Nitric oxide (NO) as a signaling molecule plays a crucial role in these responses acting alone or together with reactive oxygen species (ROS) to regulate hormonal signaling pathways, gene expression changes or protein activities. The regulatory role of NO has been demonstrated in response to abiotic and biotic stresses as well as in plant developmentally processes throughout the entire plant life (Corpas et al., 2011; Yu et al., 2014; Simontacchi et al., 2015). NO can influence protein activity, translocation and protein function by posttranslational modifications. The predominant way of NO action is the reversible $S$-nitrosylation, a covalent attachment of NO to cysteine thiols. Further modifications are the nitrosylation of metal center of metalloproteins and the irreversible nitration of protein tyrosine residues (Astier and Lindermayr, 2012; Kovacs and Lindermayr, 2013). As a free radical, NO has a very short lifetime that restrict their effect to the local microenvironment. However, $S$-nitrosylated glutathione ( $S$ nitrosoglutathione GSNO) is a quite stable NO reservoir and NO transport form. GSNO can trans-nitrosylate proteins regulating their activity/function (Lindermayr et al., 2010; Espunya et al., 2012; Corpas et al., 2013; Frungillo et al., 2014). GSNO level is regulated either by its production or by an enzymatic turnover mechanism catalyzed by GSNO reductase (GSNOR). Mutations in GSNOR gene have been shown to cause pleiotropic plant growth defects, impaired plant disease responses, heat sensitivity, and resistance to cell death (Feechan et al., 2005; Rusterucci et al., 2007; Lee et al., 2008; Kwon et al., 2012; Xu et al., 2013). The gsnor-ko plants contain elevated amount of S-nitrosothiols (SNO) and nitroso species indicating that GSNOR activity controls the level of both GSNO and indirectly protein-SNOs (Liu et al., 2001; Feechan et al., 2005; Lee et al., 2008). GSNOR, originally identified in plants and other organisms as a glutathionedependent formaldehyde dehydrogenase (GS-FDH), belongs to the class III alcohol dehydrogenase family (EC 1.1.1.1) (Martinez et al., 1996). The crystal structure of GS-FDH from mammals, yeast and plants revealed that the enzyme is a homodimer coordinating two zinc atoms per subunit (Sanghani et al., 2002; Kubienova et al., 2013). Few years later, evidence was provided that GS-FDH is involved also in the $S$-nitrosothiol metabolism (Liu et al., 2001) and GSNO degrading activity was described for Arabidopsis GS-FDH (Sakamoto et al., 2002). GSNOR is a highly conserved enzyme in mammals, yeast and plants and is essential to protect cells under nitrosative stress (Liu et al., 2001; Corpas et al., 2011).

Reactive oxygen species as oxidants and signaling molecules have a fundamental influence in almost all biological processes (Apel and Hirt, 2004). The regulated production of ROS due to biotic and abiotic stimuli is necessary to activate downstream responses (Shaikhali et al., 2012; Foyer and Noctor, 2013; Dietz, 2014). However, the excessive accumulation of ROS can lead to detrimental consequences; therefore, precise regulation of ROS level is highly important. Next to the enzymatic decomposition of ROS by catalase, ascorbate peroxidase (APX) or other enzymes in the glutathione-ascorbate cycle, the non-enzymatic way by low molecular weight antioxidants, like glutathione (GSH) and ascorbate has crucial role to balance cellular redox changes (Foyer and Noctor, 2013). ROS can modify cysteine thiols and methionine residues of redox sensitive target proteins resulting in oxidative posttranslational modifications or irreversible oxidations of proteins (Konig et al., 2012; Waszczak et al., 2015). It has been shown that these oxidative modifications affect enzyme or metal-binding activity of important signaling proteins, like protein phosphatases and mitogen-activated protein kinases (Gupta and Luan, 2003; Jammes et al., 2009; Waszczak et al., 2014) or transcription factors (Dietz, 2014).

$\mathrm{H}_{2} \mathrm{O}_{2}$ and $\mathrm{NO}$ are commonly produced during various stress conditions suggesting a strong interplay between both signaling molecules. NO accumulation induced by Verticillium dahlia toxin depends on prior $\mathrm{H}_{2} \mathrm{O}_{2}$ production (Yao et al., 2012). Further evidences supported cross-talks of ROS and NO in cryptogein-induced defense response of tobacco cells (Kulik et al., 2014) and also in systemic acquired resistance in Arabidopsis (Wang et al., 2014). $\mathrm{H}_{2} \mathrm{O}_{2}$-induced $\mathrm{NO}$ production mediates abscisic acid-induced activation of a mitogen-activated protein kinase cascade (Zhang et al., 2007) and contributes to hydrogen-promoted stomatal closure (Xie et al., 2014). Despite the evidences of the crosstalk of ROS and NO signaling, there are still gaps in that regard how they control each other level and what is the consequence of their interactions.

Therefore, the focus of this study was to investigate a direct impact of ROS on GSNOR protein and thereby on cellular NO metabolism. We show that GSNOR activity is inhibited by paraquat-induced oxidative burst in wild type Arabidopsis seedlings accompanied by an increased cellular $S$-nitrosothiol and nitrite level. Furthermore, gsnor plants accumulate GSH, which acts as redox buffer to scavenge RNS. Transcripts encoding for redox-related proteins and activities of GSH-dependent enzymes were increased. Furthermore, we measured GSNOR activity under oxidizing conditions and analyzed cysteine residues by LC-MS/MS for potential oxidative modifications. We demonstrated that oxidative conditions inhibited GSNOR activity in vitro and this inhibition correlated with $\mathrm{Zn}^{2+}$ release of GSNOR. In sum, ROS-dependent regulation of GSNOR contributes to fine-tuning of NO/SNO levels, which can act directly as a ROS scavenger and/or activate antioxidant mechanisms in response to oxidative stress.

\section{MATERIALS AND METHODS}

\section{Plant Material and Growth Conditions}

Arabidopsis thaliana (L.) Heynh (ecotype Columbia-0 and Wassilewskija) wild type seeds and knock-out mutants of the GSNOR gene (At5g43940) were obtained from GABI-kat (GABI-Kat 315D11, background Columbia-0) and FLAG T-DNA collections (Versailles Genomic Resource Centre; FLAG_298F11, background Wassilewskija). After vernalisation for 2 days $\left(4^{\circ} \mathrm{C}\right.$ in dark), plants were cultivated for 4 weeks in a climate chamber at $60 \%$ relative humidity under long-day condition $(16 \mathrm{~h}$ light $/ 8 \mathrm{~h}$ dark cycle, $20^{\circ} \mathrm{C}$ day $/ 18^{\circ} \mathrm{C}$ night regime, $100 \mu \mathrm{mol} \mathrm{m}{ }^{-2} \mathrm{~s}^{-1}$ 
photon flux density). For seed germination analyses, Arabidopsis seeds were surface sterilized and grown on half strength MS medium containing $1 \%$ sucrose in a climate chamber under long-day condition.

\section{Paraquat Treatment}

Sterile seeds were germinated and grown on half strength MS plates containing different paraquat (methyl viologen, SigmaAldrich, Steinheim, Germany) concentrations $(0.25-10 \mu \mathrm{M})$ for 1 to 2 weeks. To test tyrosine nitration, Western blot was made using anti-nitrotyrosine antibody (Merck Millipore, Darmstadt, Germany) as described (Holzmeister et al., 2015). For spray application, 1,10 , and $50 \mu \mathrm{M}$ paraquat or water (control) was sprayed onto the leaf surface of 4 -week-old plants. Leaves were collected after 1-day of treatment, frozen and kept at $-80^{\circ} \mathrm{C}$ until use. For Western-blot analysis of total protein extract made from paraquat-treated leaves, polyclonal antibody against Arabidopsis GSNOR (Agrisera, Sweden) was used.

\section{NO Fumigation}

Four-week-old plants were placed in an incubator and fumigated with $80 \mathrm{ppm}$ gaseous NO or with synthetic air without NO for $20 \mathrm{~min}$. The experimental setup consisted of controlledenvironment cabinets as well as equipment to adjust and control gaseous NO treatment. NO concentration was monitored with a Chemiluminescence Nitrogen Oxides Analyzer AC32M (Ansyco, Karlsruhe, Germany). After fumigation, the plants were placed in the growth chamber until sample collection.

\section{Cloning of AtGSNOR and Cysteine

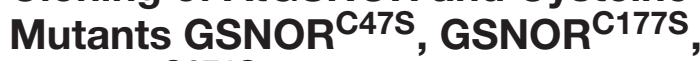 GSNOR ${ }^{\text {C271S }}$}

Total RNA isolated from wild type Arabidopsis leaves was used to produce cDNAs by SuperScript II Reverse transcriptase (Invitrogen, Carlsbad, CA, USA). For amplification of coding sequence of AtGSNOR for gateway cloning, the first PCR reaction was made using gene-specific primers (ADH2-ATG-for: 5'-ATGGCGACTCAAGGTCAG-3'; ADH2-TGA-rev: 5' -TCA TTTGCTGGTATCGAGGAC- $3^{\prime}$ ). Afterward, the second PCR reaction was performed to introduce recombination sequences (att) at the $5^{\prime}$ - and $3^{\prime}$-end using the following primers (ADH2-GW-forward: 5'-GGGGACAAGTTTGTACAAAAAAG CAGGCTTCATGGCGACTCAAGGTC-3'; ADH2-GW-reverse: 5' - GGGGACCACTTTGTACAAGAAAGCTGGGTCTCATTTG CTGGTATCGAG-3'). The resulting PCR products were cloned into pDONR221 vector (Invitrogen, Carlsbad, CA, USA) by recombination reaction using $\mathrm{BP}$ Clonase enzyme mixture according to the instructions of the manufacturer. After sequencing, the correct clone was transferred into the expression vector pDEST17 by recombination using LP Clonase enzyme mixture (Invitrogen, Carlsbad, CA, USA).

\section{Site-Directed Mutagenesis}

The modification of single nucleotide residues was performed as previously described (Lindermayr et al., 2003). Briefly, for mutation, a complementary pair of oligonucleotides was synthesized harboring the desired alterations. For amplification, $20 \mathrm{ng}$ plasmid DNA was used in a total volume of $15 \mu \mathrm{l}$, including $1 \mu \mathrm{M}$ each primer, $200 \mu \mathrm{M}$ dNTPs, and $1 \mathrm{U}$ of PfuTurbo DNA polymerase. After denaturation $\left(2 \mathrm{~min}\right.$ at $\left.94^{\circ} \mathrm{C}\right) 18$ cycles were conducted, consisting of $45 \mathrm{~s}$ at $94^{\circ} \mathrm{C}, 30 \mathrm{~s}$ at $55^{\circ} \mathrm{C}$, and $15 \mathrm{~min}$ at $72^{\circ} \mathrm{C}$, followed by a final extension step at $72^{\circ} \mathrm{C}$ for 10 min. Subsequently, the parental and hemi-parental DNA was digested with DpnI and the amplified plasmids were transformed into Escherichia coli $\mathrm{DH} 5 \alpha$. The mutation was verified by sequencing. The next primers were used to make GSNOR ${ }^{\mathrm{C} 47 \mathrm{~S}}$ forward: CTACACTGCTCTTAGTCACACCGACGCTTAC and reverse: GTAAGCGTCGGTGTGACTAAGAGCAGTGTAG; for GSNOR $^{\mathrm{C} 177 \mathrm{~S}}$ forward: GTTTGCCTTCTTGGAAGTGGTGTTC CCACTG and reverse: CAGTGGGAACACCACTTCCAAGA AGGCAAAC; for GSNOR ${ }^{\mathrm{C} 271 \mathrm{~S}}$ forward: GACTACAGCTTTGA GAGCATCGGGAATGTCTC and reverse: GAGACATTCCCG ATGCTCTCAAAGCTGTAGTC.

\section{Purification of Recombinant GSNOR and Cysteine Mutants}

For expression of the recombinant $\mathrm{N}$-terminal $\mathrm{His}_{6}$ fusion proteins the wild type pDEST17-GSNOR and the cysteine mutants GSNOR ${ }^{\mathrm{C} 47 \mathrm{~S}}$, GSNOR ${ }^{\mathrm{C} 177 \mathrm{~S}}$, GSNOR ${ }^{\mathrm{C} 271 \mathrm{~S}}$ were transformed into the E. coli strain BL21 DE3 pLysS., The LB cultures at $A_{600} \sim 0.6$ were induced with $0.1 \mathrm{mM}$ isopropyl$\beta$-D-thiogalactopyranoside and further incubate for $4 \mathrm{~h}$ at $28^{\circ} \mathrm{C}$. After induction the bacterial cells were harvested by centrifugation and stored frozen. For protein isolation the cells were resuspended in a lysis buffer [ $25 \mathrm{mM}$ Tris- $\mathrm{HCl}, \mathrm{pH} 8.0$, $1 \mathrm{mM}$ EDTA, 0.5\% Triton X-100, 20\% (v/v) glycerol, $1 \mathrm{mM}$ $\beta$-mercaptoethanol] and disrupted by sonication. Cellular debris was removed by centrifugation and the soluble fraction was purified by affinity chromatography using Ni-NTA agarose (Qiagen, Hilden, Germany). Adsorbed proteins were eluted from the matrix with elution buffer containing $25 \mathrm{mM}$ Tris- $\mathrm{HCl} \mathrm{pH}$ 8.0, $250 \mathrm{mM}$ imidazole, $10 \mathrm{mM}$ DTT, 20\% (v/v) glycerol. The eluates were aliquoted, frozen in liquid nitrogen and stored at $-80{ }^{\circ} \mathrm{C}$ until analysis. The purity was checked by SDS-PAGE and the protein concentration was measured by Bradford assay (Bio-Rad). Before the further use the elutions were desalted by Zeba-Spin column (Thermo Scientific, Rockford, IL, USA).

\section{Static Light-Scattering Analysis}

Static light scattering (SLS) experiments on recombinant GSNOR were performed at $30^{\circ} \mathrm{C}$ using a Viscotek TDA 305 triple array detector (Malvern Instruments) downstream to an Äkta Purifier (GE Healthcare) equipped with an analytical size exclusion column (Superdex 200 10/300 GL, GE Healthcare) at $4^{\circ} \mathrm{C}$. GSNOR protein was purified under reducing condition, followed by Äkta purification, than $200 \mu \mathrm{g}$ GSNOR was oxidized by $1 \mathrm{mM}$ $\mathrm{H}_{2} \mathrm{O}_{2}$. The reduced and oxidized GSNOR samples were run in $50 \mathrm{mM}$ Tris- $\mathrm{HCl} \mathrm{pH} 8.0,200 \mathrm{mM} \mathrm{NaCl}$, with or without $10 \mathrm{mM}$ DTT, respectively, at a flow rate of $0.5 \mathrm{ml} / \mathrm{min}$. The molecular masses of the samples were calculated from the refractive index and right-angle light-scattering signals using Omnisec (Malvern Instruments). The SLS detector was calibrated with a $4 \mathrm{mg} / \mathrm{ml}$ 
BSA solution with $66.4 \mathrm{kDa}$ for the BSA monomer and a $\mathrm{dn} / \mathrm{dc}$ value of $0.185 \mathrm{ml} / \mathrm{g}$ for all protein samples.

\section{Enzyme Activity Assays}

Purified GSNOR protein was re-buffered using Zeba Spin column equilibrated with $20 \mathrm{mM}$ Tris- $\mathrm{HCl} \mathrm{pH} 8.0$ buffer. GSNOR activity was determined by measuring the reaction rate of $\mathrm{NADH}$ usage at $340 \mathrm{~nm}$ in Ultrospec 3100 pro (Amersham Biosciences) spectrophotometer. The reaction buffer contained 20 mM Tris-HCl pH 8.0, 0.5 mM EDTA, 0.2 mM NADH. Serial dilutions (50-2000-fold) of recombinant His-tagged GSNOR proteins (wild type and cysteine mutants) were prepared and the reaction was started to add GSNO (Enzo Life Sciences) at a final concentration of up to $0.5 \mathrm{mM}$. Water was used instead of GSNO in the reference sample. The reaction was monitored for $5 \mathrm{~min}$ and the linear rate was corrected with a reference rate without GSNO. There was no detectable NADH oxidation without enzyme. Specific activity was calculated using a molar extinction coefficient for NADH $6.22 \mathrm{mM}^{-1} \mathrm{~cm}^{-1}$. Effect of $\mathrm{H}_{2} \mathrm{O}_{2}$, PN or NEM on GSNOR activity was analyzed by incubation of recombinant GSNOR with these compounds

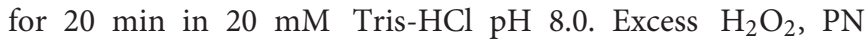
or NEM was removed by gel filtration using Zeba desalting columns (Thermo Fisher Scientific, Waltham, MA, USA). Zeba Spin columns were equilibrated with $20 \mathrm{mM}$ Tris- $\mathrm{HCl} \mathrm{pH}$ 8.0. The eluates were used to determine GSNOR activity. To analyze reversibility of $\mathrm{H}_{2} \mathrm{O}_{2}$-dependent inhibition of GSNOR, excess $\mathrm{H}_{2} \mathrm{O}_{2}$ was removed (Zeba Spin, $20 \mathrm{mM}$ Tris- $\mathrm{HCl} \mathrm{pH} \mathrm{8.0)} \mathrm{and}$ inhibited GSNOR was divided into two fractions. One fraction was treated with water, the other one was treated with $10 \mathrm{mM}$ DTT for $10 \mathrm{~min}$ at room temperature. Before measuring the activity, both samples were desalted using Zeba Spin columns equilibrated with $20 \mathrm{mM}$ Tris- $\mathrm{HCl} \mathrm{pH}$ 8.0. To analyze the effect of $\mathrm{H}_{2} \mathrm{O}_{2}$ in presence of excess $\mathrm{Zn}^{2+}$, GSNOR was treated with $0.5 \mathrm{mM} \mathrm{H}_{2} \mathrm{O}_{2}$ in presence of $0.5 \mu \mathrm{M} \mathrm{ZnSO}_{4}$ for $20 \mathrm{~min}$. Excess $\mathrm{H}_{2} \mathrm{O}_{2}$ and $\mathrm{ZnSO}_{4}$ was remove using Zeba Spin columns $(20 \mathrm{mM}$ Tris-HCl pH 8.0) and GSNOR activity was determined.

To measure GSNOR activity from plant tissue, total soluble proteins were extracted from treated seedlings or leaves in buffer of $0.1 \mathrm{M}$ Tris- $\mathrm{HCl} \mathrm{pH} 7.5,0.1 \mathrm{mM}$ EDTA, 0.2\% TritonX-100, $10 \%$ glycerol. The homogenate was centrifuged twice at $14.000 \mathrm{~g}$ for $20 \mathrm{~min}$ at $4^{\circ} \mathrm{C}$ and total protein concentration of the supernatant was measured according to Bradford using BSA as a standard. GSNOR activity was determined by incubating $100 \mu \mathrm{g}$ of protein extract in $1 \mathrm{ml}$ reaction buffer as described above.

Glutathione reductase activity assay is based on the NADPHdependent reduction of GSSG to GSH. GR activity was measured by the rate of NADPH oxidation at $340 \mathrm{~nm}$. Proteins from 2week-old seedlings were extracted with extraction buffer $(50 \mathrm{mM}$ potassium phosphate $\mathrm{pH} 7.8,0.1 \mathrm{mM}$ EDTA, $0.5 \%$ Triton X-100, 0.5\% PVP-40). $50 \mu \mathrm{g}$ total protein was incubated in $1 \mathrm{ml} \mathrm{GR}$ reaction buffer $(100 \mathrm{mM}$ potassium phosphate $\mathrm{pH} 7.8,1 \mathrm{mM}$ EDTA, $0.2 \mathrm{mM}$ NADPH). The reaction was started by addition of $100 \mu \mathrm{l}$ of $5 \mathrm{mM}$ GSSG and was monitored at $340 \mathrm{~nm}$ for $5 \mathrm{~min}$. The linear rate of reaction was corrected with a reference rate without GSSG (molar extinction coefficient for NADPH $\left.6.22 \mathrm{mM}^{-1} \mathrm{~cm}^{-1}\right)$.
Glutathione-S-Transferase (GST) activity was measured by spectrophotometrically using the artificial substrate 1-chloro-2,4dinitrobenzene (CDNB) for GSH attachment. $50 \mu \mathrm{g}$ of total protein was incubated in $1 \mathrm{ml}$ GST reaction buffer $(100 \mathrm{mM}$ potassium phosphate $\mathrm{pH} 7.8,1 \mathrm{mM}$ CDNB in $80 \%$ ethanol) and the reaction was started by adding $100 \mu \mathrm{l}$ of $10 \mathrm{mM}$ GSH. The production of GSH-CDNB conjugate was monitored at $340 \mathrm{~nm}$ [molar extinction coefficient $(\varepsilon)=9600 \mathrm{M}^{-1} \mathrm{~cm}^{-1}$ ].

\section{$\mathrm{Zn}^{2+}$ Release Assay}

Free $\mathrm{Zn}^{2+}$ ions were detected by a metallochromic indicator 4-(2pyridylazo)-resorcinol (PAR), which binds $\mathrm{Zn}^{2+}$ in a 2:1 complex and turn its color from yellow to orange with strong absorbance at $490 \mathrm{~nm}$ (Crow et al., 1997). Recombinant GSNOR (50-100 $\mu \mathrm{g}$ ) was oxidized by increasing molar excess (100-3000 to protein) of $\mathrm{H}_{2} \mathrm{O}_{2}$ for $1 \mathrm{~h}$ in $50 \mathrm{mM}$ Tris- $\mathrm{HCl} \mathrm{pH} 7.2$ and mix with $100 \mu \mathrm{M}$ PAR. The absorbance of $\mathrm{PAR}_{2}-\mathrm{Zn}$ complex was measured at $490 \mathrm{~nm}$ and the $\mathrm{Zn}$ content was calculated using $\mathrm{ZnCl}_{2}$ standard curve.

\section{Mass Spectrometric Analyses of GSNOR}

Twenty microliter of $\mathrm{H}_{2} \mathrm{O}_{2}$-treated (molar ratio of $\mathrm{H}_{2} \mathrm{O}_{2}$ to protein was 100:1 or 1000:1) or water-treated (as control) recombinant GSNOR (corresponding to approximately $8 \mu \mathrm{g}$ of protein) was incubated with $20 \mu \mathrm{l}$ of non-reducing SDS-gel loading buffer (20\% glycerol, 4\% SDS, $0.125 \mathrm{M}$ Tris- $\mathrm{HCl} \mathrm{pH}$ 6.8) containing $55 \mathrm{mM} 2$-iodoacetamide (IAA). To remove the excess of IAA completely, samples were separated under nonreducing conditions on SERVAGel TG PRiME 4-12\% (SERVA, Heidelberg, Germany). Then the gel was stained with Coomassie overnight and after de-staining the bands were excised and transferred into $1.5 \mathrm{~mL}$ reaction tubes. Reduction of cysteine residues was performed for $30 \mathrm{~min}$ at $55^{\circ} \mathrm{C}$ using $45 \mathrm{mM}$ DTT in $50 \mathrm{mM} \mathrm{NH}_{4} \mathrm{HCO}_{3}$. After removal of DTT solution, blocking was performed using $50 \mathrm{mM} S$-methyl-methanethiosulfonate (MMTS) for $30 \mathrm{~min}$, then the gel slices were washed three times using $50 \mathrm{mM} \mathrm{NH} \mathrm{HCO}_{3}$. The in-gel digestion was performed overnight using $500 \mathrm{ng}$ bovine chymotrypsin (Roche Diagnostics, Mannheim, Germany) or 70 ng trypsin (Promega, Fitchburg, WI, USA). Peptides were separated on NanoLC Ultra chromatography system (Eksigent, Redwood City, CA, USA) coupled to an LTQ Orbitrap XL mass analyzer (Thermo Fisher Scientific, San Jose, CA, USA). Mobile phase A was $0.1 \%$ formic acid and mobile phase B was $84 \%$ acetonitrile/ $0.1 \%$ formic acid. For separation, a reversed phase nano-column (Reprosil-Pur C18 AQ, $2.4 \mu \mathrm{m} ; 150 \mathrm{~mm} \times 75 \mu \mathrm{m}$, Dr. Maisch, AmmerbuchEntringen, Germany) at a flow rate of $280 \mathrm{nl} / \mathrm{min}$ was used. The separation method consisted of two linear gradients (1-30\% B in $120 \mathrm{~min}$ and $30-60 \% \mathrm{~B}$ in $10 \mathrm{~min}$ ). Mass spectra were acquired in cycles of one MS Orbitrap scan, followed by five data dependent ion trap MS/MS scans (CID, collision energy of 35\%). MS spectra were searched using MASCOT 2.4 (Matrix Science, London, UK) using the $A$. thaliana subset of the SwissProt Database and the following parameters: (a) Variable modifications: Dioxidation (C), Trioxidation (C), Methylthio (C), Carbamidomethyl (C), Oxidation (M); (b) Enzyme: none, (c) Peptide charge: 1+, 2+, and 3+; (d) Peptide tol. \pm : $10 \mathrm{ppm}$; (e) MS/MS tol. \pm : 
0.8 Da. MASCOT DAT files were imported into the Scaffold software package (Proteome Software Inc., Portland, OR, USA) and filtered for hits with a confidence of $99 \%$ at the protein level and $95 \%$ for individual peptides.

\section{Microarray Analysis}

Total RNA from 4 to 5-week old rosette leaves of Wassilewskija Arabidopsis WT and gsnor was isolated using RNeasy Plant Mini Kit (Qiagen, Germany) according to the manufacturer's instructions. Quality checking and quantification of RNA isolates were carried out using Agilent RNA 6000 Nano kit on Agilent 2100 BioAnalyzer. Microarray analysis was performed on Agilent platform using the technique "One color Microarray-based Gene Expression Analysis" according to the protocol described in the Agilent manual. The raw expression data of three biological replicates per genotype was analyzed using GeneSpring GX software tool. Statistical analysis were carried out to identify the differentially expressed genes $(p<0.05)$ between the two genotype using One Way Anova analysis with the BenjaminiHochberg multiple test correction (FDR) and SNP Post hoc test. From the gene list, those ones regulated at least by twofold differences were selected for downstream analysis. Microarray data are available in the ArrayExpress database ${ }^{1}$ under accession number E-MTAB-4756.

\section{Determination of Glutathione}

The amount of the reduced and oxidized glutathione was determined in 2-week-old seedlings using the GR-based recycling assay described previously (Queval and Noctor, 2007). Furthermore, total glutathione, cysteine and $\gamma$-glutamylcysteine content were measured by reverse-phase HPLC after NO fumigation experiment. Briefly, $200 \mathrm{mg}$ leaf material was extracted in $0.1 \mathrm{M} \mathrm{HCl}$. Subsequently, all low molecular weight thiols were reduced by addition of DTT and then derivatized with $10 \mathrm{mM}$ monobromobimane as described previously (Wirtz et al., 2004). Samples were analyzed by reverse-phase HPLC and fluorescence excitation at $380 \mathrm{~nm}$.

\section{Determination of Ascorbate}

The amount of the reduced and total ascorbate was determined as described by Queval and Noctor (2007). Four weeks old Arabidopsis plants were sprayed with $0,1,10$, or $50 \mu \mathrm{M}$ of paraquat, harvested and stored in $-80^{\circ} \mathrm{C}$ until use. The amount of reduced ascorbate (ASC) was measured at $265 \mathrm{~nm}$ in a Tecan plate reader before and after incubation with ASC oxidase. ASC oxidase converts the reduced ASC to the non-absorbing oxidized form. For determination of total ASC, the oxidized ASC was first reduced to ASC by adding $1 \mathrm{mM}$ DTT for $30 \mathrm{~min}$, then total ASC was measured as above. ASC standard was used to calculate the amount of ASC.

\section{In situ Staining of Diaminobenzidine (DAB) and Nitroblue Tetrazolium (NBT)}

For detection of $\mathrm{H}_{2} \mathrm{O}_{2}$, paraquat or water treated Arabidopsis seedlings were vacuum infiltrated with $0.1 \%$

\footnotetext{
${ }^{1}$ http://www.ebi.ac.uk/arrayexpress
}

3,3'-Diaminobenzidine (DAB) in $10 \mathrm{mM}$ MES pH 6.5 solution, washed three times with water and incubated for $45 \mathrm{~min}$ at RT in light. After staining, plants were destained with $90 \%$ ethanol at $60^{\circ} \mathrm{C}$. The brown precipitate shows the presence of $\mathrm{H}_{2} \mathrm{O}_{2}$ in the cell and tissue.

Arabidopsis plants were vacuum infiltrated with nitroblue tetrazolium (NBT) $[50 \mathrm{mM}$ potassium phosphate/pH 6,4; $10 \mathrm{mM}$ $\left.\mathrm{NaN}_{3} ; 0,1 \%(\mathrm{w} / \mathrm{v}) \mathrm{NBT}\right]$ solution, incubated for $45 \mathrm{~min}$ in dark and washed three times with water. Afterward, plants were destained with $90 \%$ ethanol at $60^{\circ} \mathrm{C}$.

\section{Determination of Nitrosothiols and Nitrite}

Total nitrite, nitrate, and nitrosothiol content were measured using a Sievers 280i nitric oxide analyser (GE Analytical Instruments, Boulder, CO, USA). Proteins were extracted from rosettes using extraction buffer $(137 \mathrm{mM} \mathrm{NaCl}, 0,027 \mathrm{mM}$ $\mathrm{KCl}, 0,081 \mathrm{mM} \mathrm{Na} 2 \mathrm{HPO}_{4} \cdot 2 \mathrm{H}_{2} \mathrm{O}, 0,018 \mathrm{mM} \mathrm{NaH} \mathrm{PO}_{4}$ ). Leaf protein extract was injected into the purging vessel containing $3.5 \mathrm{ml}$ of acidified $\mathrm{KI} / \mathrm{I}_{3}{ }^{-}$solution (reducing agent) at $30^{\circ} \mathrm{C}$. The recorded $\mathrm{mV}$ signals were plotted against a calibration curve produced using known concentrations of sodium nitrite solution to quantify the nitrite level. To estimate the $S$-nitrosothiol content (RSNO), the above protocol was repeated by pre-treating the leaf protein extract with $20 \mathrm{mM}$ sulphanilamide (in $1 \mathrm{M} \mathrm{HCl}$ ) at the ratio of 9:1. For nitrate quantification, the reducing agent was replaced with vanadium chloride at $95^{\circ} \mathrm{C}$. The recorded $\mathrm{mV}$ signals were plotted against a calibration curve produced using known concentrations of sodium nitrate solution to quantify the nitrate levels.

\section{Statistical Analysis}

For multiple comparisons, analysis of variance was performed by Anova (one way or two way) followed by Holm-Sidak test. For pairwise comparison, Student's $t$-test was used. The level of significance is indicated in each figure.

\section{RESULTS}

\section{Paraquat-Induced Inhibition of GSNOR Activity}

$S$-nitrosoglutathione-reductase controls intracellular levels of SNOs and thereby this enzyme is important for NO homeostasis. Paraquat (1,1'-dimethyl-4,4'-bipyridinium dichloride) is an herbicide, which induces the accumulation of ROS, such as superoxide, $\mathrm{H}_{2} \mathrm{O}_{2}$ and other deleterious oxygen radicals (Dodge, 1971; Babbs et al., 1989) and is a good tool to investigate the effect of ROS on GSNOR activity in vivo. Four week old Arabidopsis plants (Col-0) were sprayed with this herbicide. Paraquat treatment for $24 \mathrm{~h}$ significantly decreased GSNOR activity in a dose-dependent manner (Figure 1A). Application of $50 \mu \mathrm{M}$ paraquat resulted in $40 \%$ enzyme inhibition, which could be restored with $10 \mathrm{mM}$ of the reducing agent 1,4-dithiothreitol (DTT) suggesting that oxidative modification(s) are responsible for inhibition of GSNOR activity. Moreover, immunoblot analysis using GSNOR-specific antibody demonstrated only 
A

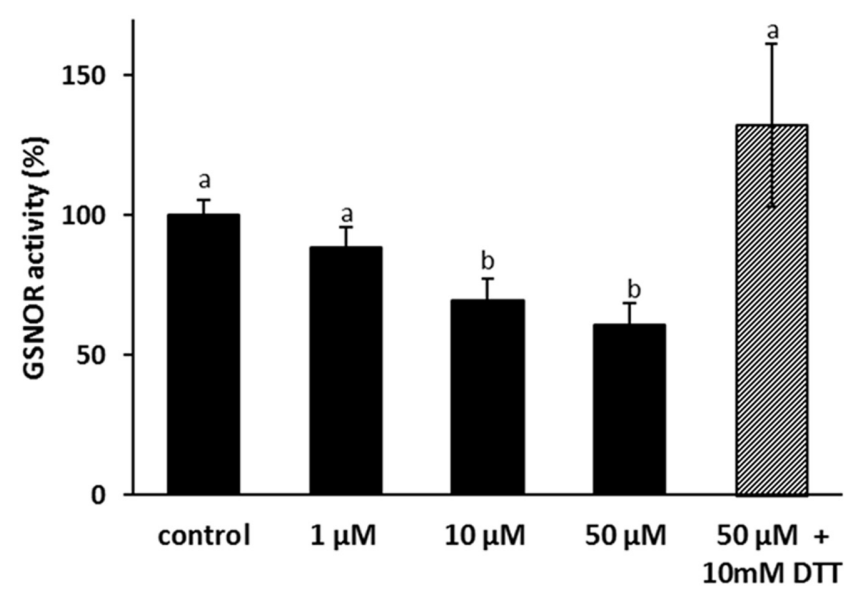

c

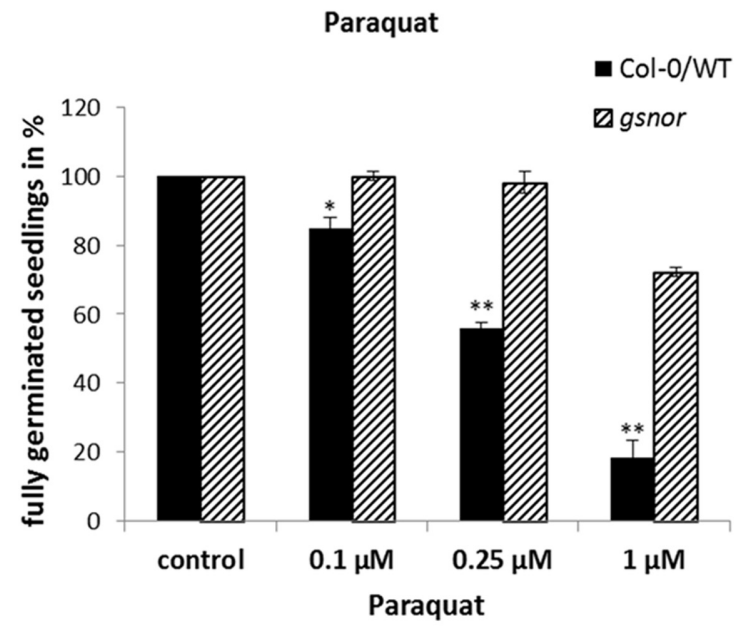

B

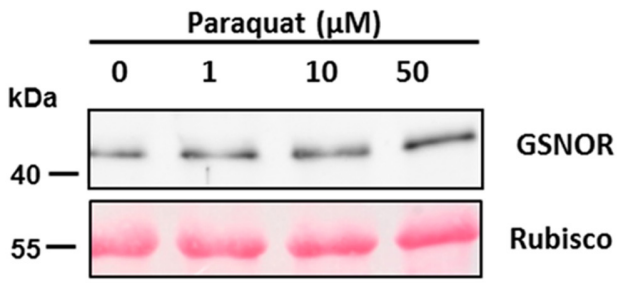

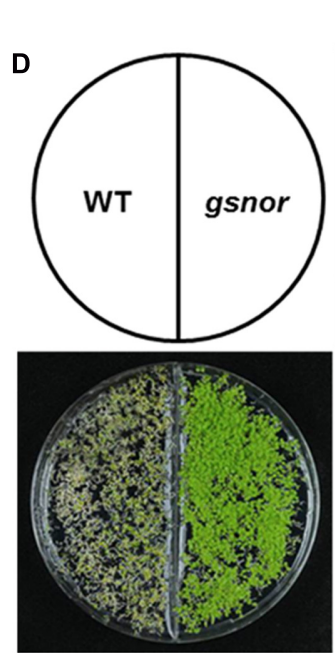

$1 \mu \mathrm{M}$ Paraquat

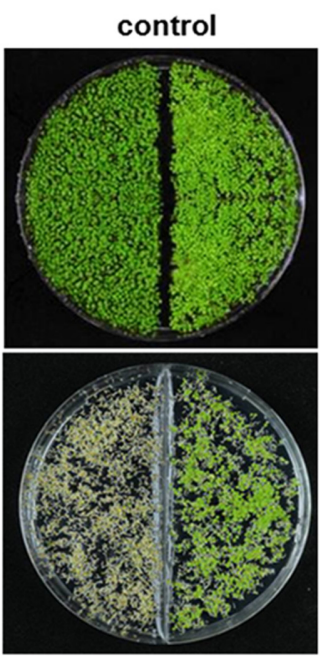

$10 \mu \mathrm{M}$ Paraquat

FIGURE 1 | Inhibition of GSNO-reductase (GSNOR) activity in vivo by paraquat and tolerance of gsnor mutants to oxidative stress. (A) Measurement of GSNOR activity from crude leaf extracts of 4-week-old Arabidopsis plants exposed to different paraquat concentrations for $24 \mathrm{~h}$. For restoring enzyme activity, $10 \mathrm{mM}$ DTT was added to the extract before the measurement (gray bar). Values are expressed as percentage of water treated control plants (specific activity varies 49.2-91.1 nmol NADH min ${ }^{-1} \mathrm{mg}^{-1}$ ) and represent the mean \pm SD calculated from three biological replicates. Different letters indicate significant differences, $p<0.05$, Anova. (B) Western blot of paraquat-treated plant extracts using GSNOR-specific antibody. Ponceau staining of Rubisco protein represents the equal loading. (C) Germination rates of 1-week-old Col-0 WT and gsnor mutant growing on $0.1,0.25$, and $1 \mu \mathrm{M}$ paraquat-containing media. The germination rate was calculated by counting fully germinated seedlings with open cotyledons and is presented in percentage of control (without paraquat). ${ }^{*} p<0.05$, ${ }^{* *} p<0.005$ indicate significant differences between WT and gsnor. (D) Representative pictures of WT and gsnor seedlings germinated on paraquat-containing media. Control is without paraquat.

a slight change of GSNOR protein amount during paraquat treatment (Figure 1B). The accumulation after treatment with $50 \mu \mathrm{M}$ paraquat is around 1.3 -fold in comparison to the control sample and might partly compensate for the paraquat-induced inhibition of GSNOR.

To study the physiological function of paraquat/ROS-induced GSNOR inhibition, plants lacking GSNOR function were analyzed for their response to paraquat treatment. Interestingly, Chen et al. (2009) previously observed that GSNOR plays a role in regulating paraquat-induced cell death in plant cells through modulating intracellular $\mathrm{NO}$ level. We used two T-DNA insertion alleles for GSNOR (background Col-0 and
Wassilewskija, named gsnor and WS/gsnor, respectively) to test their germination and growth in presence of paraquat. Seeds of WT and gsnor plants were cultivated on MS media containing $0-1 \mu \mathrm{M}$ paraquat and the germination rate was determined by counting fully germinated seedlings with two open cotyledons. The germination rate of WT plants was strongly reduced to $20 \%$ in presence of $1 \mu \mathrm{M}$ paraquat (Figure 1C). In contrast, the germination rate of gsnor plants was significantly higher (72\%) at this paraquat concentration (Figure 1C). Similar results could be observed using the T-DNA insertion line in Wassilewskija background (WS/gsnor; Supplementary Figure S1A). Paraquat induced cell death phenotype of WT seedlings was obvious using 
higher paraquat concentration ( 1 and $10 \mu \mathrm{M}$ ) by the yellowishbrown colored cotyledons and restricted growth (Figure 1D). Interestingly, gsnor mutant showed an enhanced tolerance even in the presence of $10 \mu \mathrm{M}$ paraquat demonstrated by green viable seedlings.

Paraquat-induced $\mathrm{O}_{2}^{-}$can react with $\mathrm{NO}$ resulting in $\mathrm{ONOO}^{-}$production, which can oxidize cysteine residues or nitrate tyrosine residues of proteins. Protein tyrosine nitration is a marker for pathological processes in cell death. WT seedlings germinated on $0.5 \mu \mathrm{M}$ paraquat showed stronger tyrosine nitration than gsnor seedlings (Supplementary Figure S1B) suggesting a weaker cell death phenotype for gsnor mutant, which correlates with the observed visible effect of more green seedlings (Figure 1D).

\section{Paraquat-Induced Changes in NO Metabolism}

Since GSNOR activity is important for SNO homeostasis, intracellular SNO levels were analyzed after paraquat treatment. WT and gsnor plants were sprayed with 1,10 , and $50 \mu \mathrm{M}$ paraquat and total cellular SNO content was determined. SNO levels increased in paraquat-treated WT plants from $15 \mathrm{pmol}$ $\mathrm{mg}^{-1}$ up to $40 \mathrm{pmol} \mathrm{mg}^{-1}$ (50 $\mathrm{MM}$ paraquat) (Figure 2A). The gsnor mutant has already elevated SNO content under

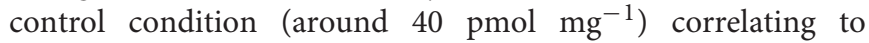
the loss of GSNOR function. Paraquat application did not result in significant further accumulation of SNOs in gsnor plants (Figure 2A). In the living cell $\mathrm{NO}$ can be oxidized to give nitrite, which would indicate freshly produced NO. Therefore, we measured nitrite content from WT and gsnor plants treated with paraquat. The nitrite level increased in both plant lines in a similar degree in the presence of increasing herbicide concentrations (Figure 2B); however, the nitrite content was significantly higher over the treatment in gsnor plants.

\section{gsnor Plants Have Higher GSH-Dependent Antioxidant Capacity}

Resistance against oxidative stress is often related to an enhanced cellular antioxidant capacity. Therefore, the amount of reduced and oxidized glutathione (GSH and GSSG, respectively) was measured in WT and gsnor seedlings germinated on media with and without $0.5 \mu \mathrm{M}$ paraquat for 14 days. GSH level of untreated gsnor plants was about twofold higher than of WT plants and the content increased upon paraquat treatment about four and threefold in WT and gsnor plants, respectively (Figure 3A). About 10\% of the glutathione pool was oxidized under control conditions in both plant lines demonstrating that the redox status is the same in WT and gsnor plants (GSH:GSSG ratio, Figure $3 \mathbf{A}$ ). Germination on paraquat-containing media for 14 days resulted in increased total glutathione content in both plant lines; however, the glutathione pool was more reducing in the gsnor mutant than in WT (GSH:GSSG ratio around 30 and 20, respectively, Figure 3A). This result indicates that gsnor may cope better with a long-term paraquat treatment than WT plants to keep cellular redox condition more reducing.
In correlation with the increased level of glutathione, we measured around 20\% higher activity for glutathione reductase (GR) enzyme in untreated gsnor plants in comparison to WT plants (Figure 3B). GR reduces GSSG to GSH in a NADPH-dependent manner. In both lines, GR activity increased by around $30 \%$ after paraquat treatment. The glutathione $S$-transferase (GST) activity was also higher (with 15\%) in untreated gsnor plants than in WT and the GST activity increased in both plant lines after paraquat-treatment by around $10 \%$ (Figure 3B). Ascorbate is another important cellular reductant inter-connected to the anti-oxidative response in chloroplast. However, although the levels of reduced ascorbate were higher in gsnor plants after paraquat-treatment, the differences were significant only at high paraquat concentrations (Supplementary Figure S2). All these results suggest that the enhanced GSH levels and enhanced activities of GSH-dependent enzymes contribute to the paraquat tolerant phenotype of gsnor plants.

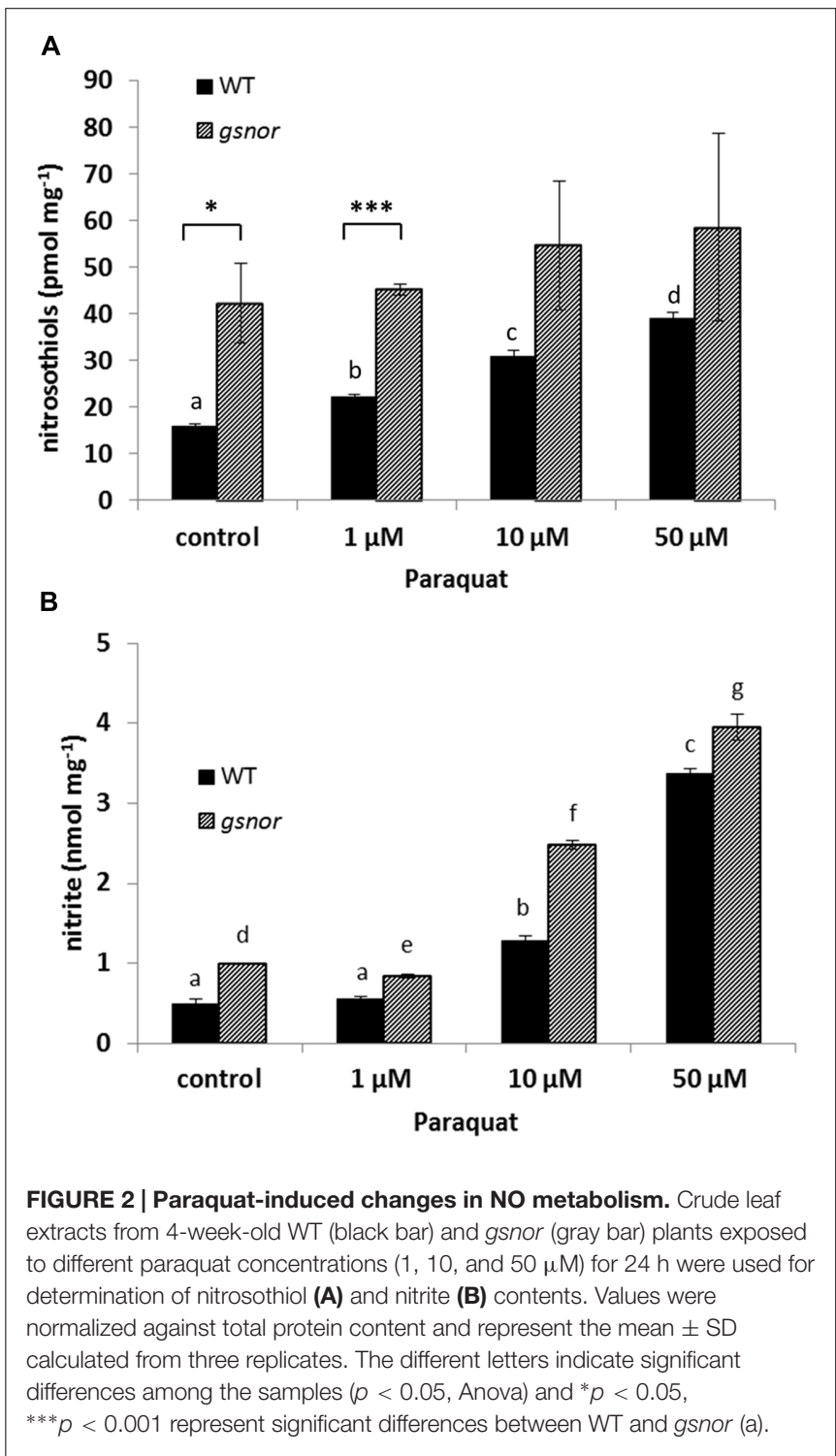




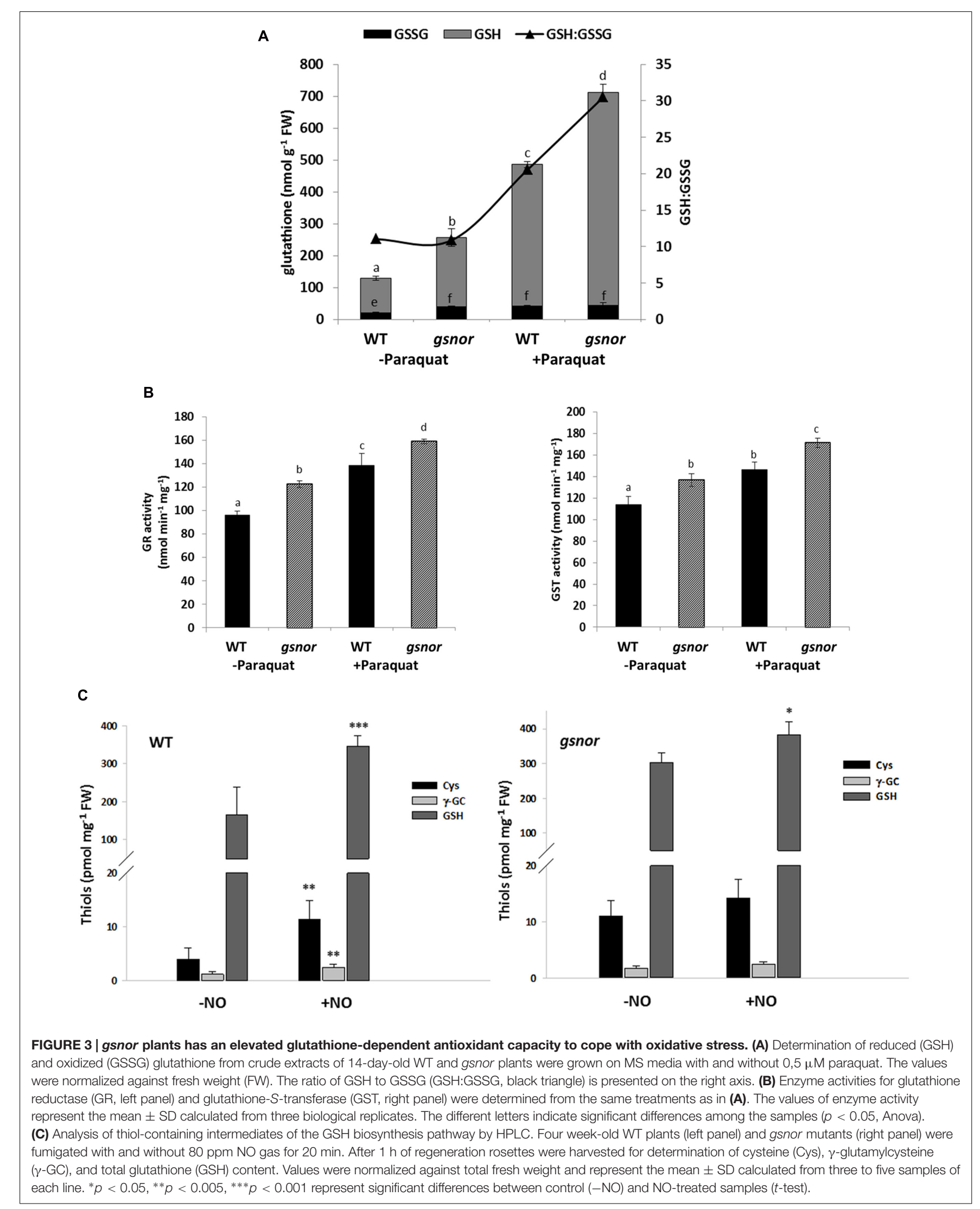


TABLE 1 | Candidate genes involved in $\mathrm{H}_{2} \mathrm{O}_{2}$ metabolism.

\begin{tabular}{|c|c|c|}
\hline Gene & $\begin{array}{l}\text { Fold- } \\
\text { change }\end{array}$ & Protein \\
\hline \multicolumn{3}{|l|}{ Upregulated } \\
\hline AT4G16270 & 13.66 & Peroxidase 40 (PER40) (P40) \\
\hline AT1G44970 & 12.88 & Peroxidase, putative \\
\hline AT5G47000 & 11.94 & Peroxidase, putative \\
\hline AT5G64100 & 5.31 & Peroxidase, putative \\
\hline AT1G14540 & 5.27 & Anionic peroxidase, putative \\
\hline AT5G64110 & 5.15 & Peroxidase, putative \\
\hline AT5G64120 & 4.13 & Peroxidase, putative \\
\hline AT5G39580 & 3.84 & Peroxidase, putative \\
\hline AT3G03670 & 3.80 & Peroxidase, putative \\
\hline AT5G05340 & 3.60 & Peroxidase, putative \\
\hline AT4G33420 & 2.95 & Peroxidase, putative \\
\hline AT5G06720 & 2.92 & Peroxidase, putative \\
\hline AT4G08770 & 2.23 & Peroxidase, putative \\
\hline AT4G37520 & 2.12 & Peroxidase 50 (PER50) (P50) (PRXR2) \\
\hline AT5G19890 & 2.09 & Peroxidase, putative \\
\hline AT5G15180 & 2.05 & Peroxidase, putative \\
\hline AT1G60740 & 18.77 & Peroxiredoxin type 2 , putative \\
\hline AT1G65970 & 6.99 & TPX2 (thioredoxin-dependent peroxidase 2) \\
\hline AT1G69880 & 6.20 & ATH8 (thioredoxin H-type 8) \\
\hline AT5G61440 & 3.31 & ACHT5 (ATYPICAL CYS HIS RICH THIOREDOXIN 5) \\
\hline AT1G59730 & 2.48 & ATH7 (thioredoxin H-type 7) \\
\hline AT2G29490 & 33.42 & ATGSTU1 (GLUTATHIONE S-TRANSFERASE TAU 1) \\
\hline AT1G17180 & 32.23 & ATGSTU25 (GLUTATHIONE S-TRANSFERASE TAU 25) \\
\hline AT2G29480 & 28.71 & ATGSTU2 (GLUTATHIONE S-TRANSFERASE TAU 2) \\
\hline AT1G17170 & 11.78 & ATGSTU24 (GLUTATHIONE S-TRANSFERASE TAU 24) \\
\hline AT2G29470 & 5.73 & ATGSTU3 (GLUTATHIONE S-TRANSFERASE TAU 3) \\
\hline AT1G69930 & 5.61 & ATGSTU11 (GLUTATHIONE S-TRANSFERASE TAU 11) \\
\hline AT1G59670 & 4.15 & ATGSTU15 (GLUTATHIONE S-TRANSFERASE TAU 15) \\
\hline AT3G09270 & 3.94 & ATGSTU8 (GLUTATHIONE S-TRANSFERASE TAU 8) \\
\hline AT1G74590 & 3.74 & ATGSTU10 (GLUTATHIONE S-TRANSFERASE TAU 10) \\
\hline AT2G29440 & 3.65 & ATGSTU6 (GLUTATHIONE S-TRANSFERASE TAU 6) \\
\hline AT2G29420 & 3.41 & ATGSTU7 (GLUTATHIONE S-TRANSFERASE TAU 7) \\
\hline AT1G69920 & 2.38 & ATGSTU12 (GLUTATHIONE S-TRANSFERASE TAU 12) \\
\hline AT2G29460 & 2.31 & ATGSTU4 (GLUTATHIONE S-TRANSFERASE TAU 4) \\
\hline \multicolumn{3}{|c|}{ Downregulated } \\
\hline AT4G11290 & -2.04 & Peroxidase, putative \\
\hline AT4G31870 & -2.24 & ATGPX7 (glutathione peroxidase 7) \\
\hline AT4G23340 & -5.61 & Oxidoreductase, 2OG-Fe(II) oxygenase family protein \\
\hline AT1G55290 & -3.28 & Oxidoreductase, 2OG-Fe(II) oxygenase family protein \\
\hline AT1G49390 & -2.59 & Oxidoreductase, 2OG-Fe(II) oxygenase family protein \\
\hline AT2G44800 & -2.36 & Oxidoreductase, 2OG-Fe(II) oxygenase family protein \\
\hline
\end{tabular}

Gene expression analysis of redox-regulated genes by transcript profiling of gsnor under normal growing condition. Fold change $(p<0.05)$ represents transcript abundance in gsnor relative to WT plant.

Taken into consideration that loss of GSNOR function results in elevated SNO/NO and GSH levels, which are both important for resistance against paraquat-induced oxidative stress, we analyzed the interplay between both components. Four-week-old WT and gsnor plants were fumigated with $80 \mathrm{ppm} \mathrm{NO}$ gas for $20 \mathrm{~min}$ to mimic NO burst and levels of low molecular weight thiols of the GSH biosynthesis pathway such as cysteine, $\gamma$-glutamylcysteine and total glutathione were determined. NO fumigation resulted in an increase of these compounds in both plant lines (Figure 3C). In addition, untreated gsnor plants had around twofold higher levels of cysteine and glutathione than WT plants, indicating a connection between $\mathrm{SNO} / \mathrm{NO}$ and the GSH biosynthesis pathway.

\section{Genes Involved in Antioxidant Mechanisms Are Upregulated in gsnor Mutant}

To further demonstrate the presence of a pre-induced antioxidant system in gsnor plants, a microarray analysis was performed of 4-week-old rosettes of gsnor and WT plants. Out of 2159 genes, which were differentially regulated, 1407 genes were significantly upregulated and 752 genes were significantly downregulated by at least twofold in gsnor mutant (Supplementary Table S1) (ArrayExpress accession number E-MTAB-4756). Gene enrichment analysis of the regulated genes using VirtualPlant 1.3 platform (Katari et al., 2010) revealed that the most significantly enriched functional categories of the upregulated genes were the catalytic-, hydrolase-, oxidoreductase-, and glutathione transferase-activities (Supplementary Table S2). Among these functional categories, we focused on genes related to processes metabolizing $\mathrm{H}_{2} \mathrm{O}_{2}$. Within the upregulated genes, 16 genes encoding for peroxidases were identified. Peroxidases are heme-containing enzymes that use hydrogen peroxide as the electron acceptor to catalyze a number of oxidative reactions (Table 1). Moreover, genes encoding for thioredoxins (H-type 7, H-type 8, and atypical ACHT5) and thioredoxin-dependent peroxidases were upregulated in gsnor plants (Table 1). The third subgroup of upregulated genes are encoding for 13 members of the Tau subfamily of GSTs (Table 1). The list of downregulated genes contains only a few transcripts related to redox-regulation, for example one putative peroxidase and a glutathione peroxidase 7 (Table 1). Moreover, four member of the $\mathrm{Fe}(\mathrm{II})$ and 2-oxoglutaratedependent dioxygenase family with an oxidoreductase activity was found to be downregulated. In sum, the transcript profile analysis of gsnor plants suggests a pre-induced antioxidant system under normal growth condition, which can help to defend plants against subsequent oxidative stress.

In line with the transcriptional data, we have analyzed the $\mathrm{O}_{2}{ }^{-}$and $\mathrm{H}_{2} \mathrm{O}_{2}$ level in WT and gsnor plants after paraquat treatment. Ten days old seedlings grown on MS media were treated with $25 \mu \mathrm{M}$ paraquat and vacuum infiltrated with either nitroblue tetrazolium (NBT) for $\mathrm{O}_{2}{ }^{-}$detection (Doke, 1983) or DAB for $\mathrm{H}_{2} \mathrm{O}_{2}$ accumulation (Thordal-Christensen et al., 1997) (Supplementary Figure S3). No obvious difference in $\mathrm{O}_{2}{ }^{-}$accumulation could be observed in paraquat-treated WT and gsnor plants (Supplementary Figure S3A). In contrast, $\mathrm{H}_{2} \mathrm{O}_{2}$ accumulation was lower in leaves of gsnor plants in comparison to WT plants (Supplementary Figure S3B) suggesting a higher capacity to metabolize $\mathrm{H}_{2} \mathrm{O}_{2}$ in gsnor line. 


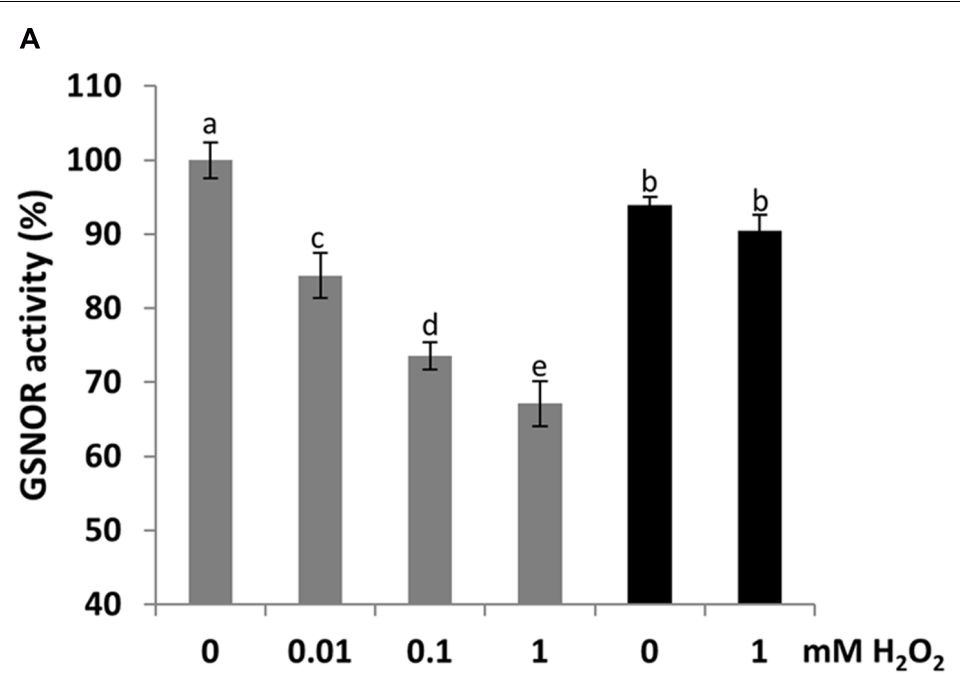

B

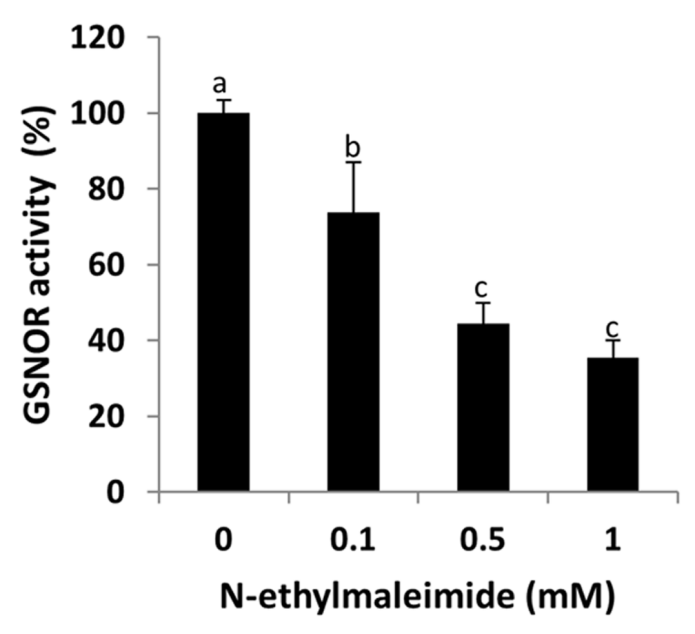

C

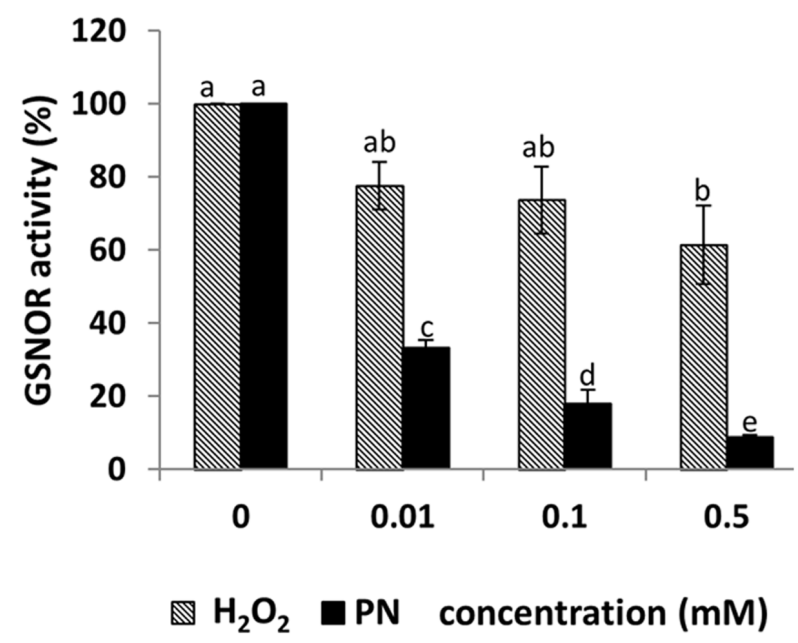

FIGURE 4 | Dose-dependent inhibition of GSNOR activity by oxidation in vitro. Measurements of GSNO reducing activity of GSNOR protein. Recombinant GSNOR $(1 \mu \mathrm{g})$ was incubated with indicated concentrations of $\mathrm{H}_{2} \mathrm{O}_{2}$ (A), N-ethylmaleimide (B), and peroxynitrite (PN) and $\mathrm{H}_{2} \mathrm{O}_{2}$ (C). For restoring GSNOR activity,

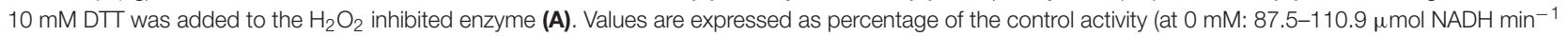
$\mathrm{mg}^{-1}$ varied among independent purifications) and represent the mean \pm SD calculated from three independent assays. Different letters indicate significant differences ( $p<0.05$, Anova).

\section{$\mathrm{H}_{2} \mathrm{O}_{2}$-Dependent Inhibition of GSNOR Activity In vitro}

To analyze whether $\mathrm{H}_{2} \mathrm{O}_{2}$ affect Arabidopsis GSNOR activity, recombinant protein was incubated with increasing concentrations of $\mathrm{H}_{2} \mathrm{O}_{2} \quad(0.01,0.1$, and $1 \mathrm{mM})$. A dosedependent reduction of the GSNOR activity was observed (Figure 4A). Treatment with $10 \mu \mathrm{M} \mathrm{H} \mathrm{H}_{2} \mathrm{O}_{2}$ caused already $15 \%$ inhibition, which further decreased to $35 \%$ in the presence of $1 \mathrm{mM} \mathrm{H}_{2} \mathrm{O}_{2}$. Incubation of inhibited GSNOR with $10 \mathrm{mM}$ of the reducing agent DTT partly restored the activity, concluding that enzyme inhibition was a result of reversible and irreversible modifications of one or several redox-sensitive amino acid residues. Treatment with the sulfhydryl-blocking agent $N$-ethylmaleimide also inhibited the activity of GSNOR to $40 \%$ demonstrating that cysteine residues are important for its activity (Figure 4B). Peroxynitrite $\left(\mathrm{ONOO}^{-}\right)$is formed from the reaction of superoxide $\left(\mathrm{O}_{2}{ }^{-}\right)$and $\mathrm{NO}$ and acts as a potent oxidant on cysteine residues and as a nitrating agent on tyrosine residues of proteins (Arasimowicz-Jelonek and Floryszak-Wieczorek, 2011). Treatment of GSNOR with $10 \mu \mathrm{M}$ of peroxynitrite reduced the activity by $70 \%$ (Figure 4C). Western blot analysis using 3-nitrotyrosine specific antibodies to detect tyrosine nitration of peroxynitrite-treated GSNOR protein did not show any nitration (data not shown) indicates that the peroxynitrite-dependent loss of GSNOR activity is probably due to the oxidation of cysteine(s) (Zeida et al., 2013). 


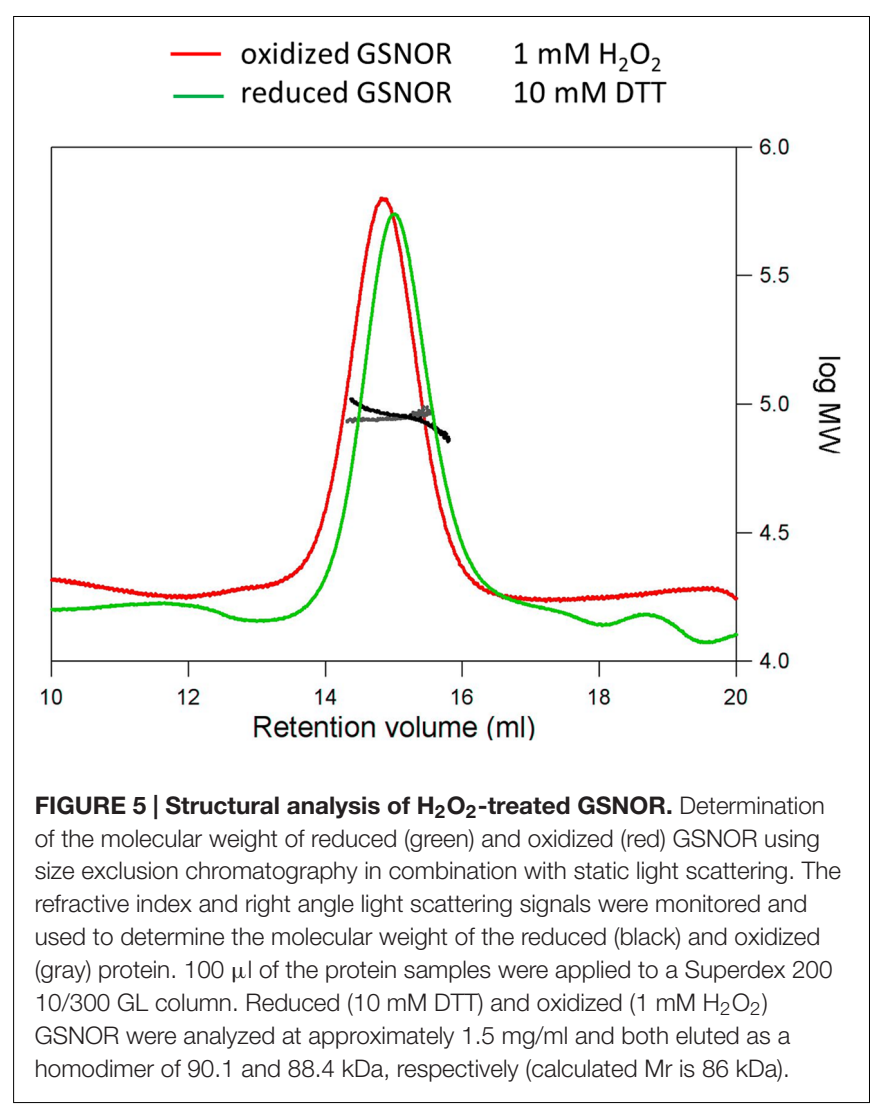

\section{Structural Analysis of $\mathrm{H}_{2} \mathrm{O}_{2}$-treated GSNOR}

As known from the crystal structure, GSNOR is a homodimer protein. To analyze, whether oxidative conditions cause changes in the native structure of GSNOR SLS experiments with reduced and oxidized recombinant GSNOR were performed. Figure 5 shows that GSNOR protein is detected as dimer under both reducing (10 $\mathrm{mM}$ DTT) and oxidizing (1 $\mathrm{mM}$ $\mathrm{H}_{2} \mathrm{O}_{2}$ ) conditions with no significant difference between both states. The determined molecular weight was 90.1 and $88.4 \mathrm{kDa}$ for reduced and oxidized GSNOR, respectively, which corresponds to the calculated weight of dimer $\left(86 \mathrm{kDa}\right.$ for $\mathrm{His}_{6}$ GSNOR).

Shifts in the electrophoretic mobility of proteins are diagnostic for the presence of oxidative modifications, like cysteine oxidations or formation of disulfide bridges (Benezra, 1994; Mahoney et al., 1996; Despres et al., 2003). Therefore, we treated recombinant GSNOR with $10-500 \mu \mathrm{M} \quad \mathrm{H}_{2} \mathrm{O}_{2}$ and DTT and investigated its running behavior by nonreducing SDS PAGE (Supplementary Figure S4). We could not observe a defined shift in the mobility of the oxidized proteins, but the more diffuse protein bands with increasing concentration of $\mathrm{H}_{2} \mathrm{O}_{2}$ may indicate the presence of several different oxidative modifications. Subsequent treatment of oxidized GSNOR with $10 \mathrm{mM}$ DTT resulted in a sharp single band demonstrating the reversibility of the oxidative modifications.

\section{$\mathrm{H}_{2} \mathrm{O}_{2}$ Treatment of GSNOR Results in Oxidative Modification of Multiple Cysteine Residues}

The thiol group of cysteine residues is susceptible to oxidation resulting in a formation of sulfenic, sulfinic, or sulfonic acids, the latter two are irreversible modifications. Moreover, disulfide bridges can be formed. Since GSNOR has 15 cysteine residues, we analyzed their oxidative modifications by nano LC-MS/MS spectrometry (Supplementary Figure S5). Recombinant GSNOR was purified under reducing condition, than was oxidized with $500 \mu \mathrm{M} \mathrm{H} \mathrm{H}_{2} \mathrm{O}_{2}$ (equivalent to 100:1 molar ratio of $\mathrm{H}_{2} \mathrm{O}_{2}$ to GSNOR protein) and with $5 \mathrm{mM} \mathrm{H}_{2} \mathrm{O}_{2}$. Afterward, free cysteine residues were blocked with iodoacetamide and reversibly modified cysteine residues were reduced with DTT and labeled with $S$-methyl-methanethiosulfonate (MTHIO). After chymotryptic digestion, the cysteine containing peptides were analyzed for their modifications by nano-LC-MS/MS. Peptides containing Cys94, Cys99, Cys102, and Cys105 could not be detected at all. All other cysteine residues could be identified in its reduced form and the average amount of free thiols $(-\mathrm{SH})$ was $90 \%$ in the water treated samples (Figure 6A). Increasing concentrations of $\mathrm{H}_{2} \mathrm{O}_{2}$ increased the amount of oxidized cysteine residues. We identified both reversibly (MTHIOlabeled) and irreversibly (sulfinic or sulfonic acids, $\mathrm{SO}_{\mathbf{x}} \mathrm{H}$ ) modified cysteine residues (Supplementary Figure S5). According to the increasing concentration of $\mathrm{H}_{2} \mathrm{O}_{2}$ the average frequency of MTHIO-labeled peptides increased from $17 \%$ to around $40 \%$ and the $\mathrm{SO}_{\mathrm{x}} \mathrm{H}$-modified cysteines from 8 to 55\% (Figure 6A). Three cysteine residues (Cys47, Cys177, and Cys271) are located in the substrate-binding site of GSNOR highlighted in the three-dimensional structure of Arabidopsis GSNOR (Figure 6B). Cys47 and Cys177 are coordinating the catalytic $\mathrm{Zn}^{2+}$ together with His69 and water molecule. $\mathrm{H}_{2} \mathrm{O}_{2}$ treatment increased the amount of oxidative modifications for both $\mathrm{Zn}^{2+}$-coordinating cysteines (Figure 6C). Around 35\% of Cys47 was already oxidized in water-treated GSNOR and the abundance of both MTHIO and $\mathrm{SO}_{\mathrm{x}} \mathrm{H}$-modification increased significantly in the presence of 0.5 and $5 \mathrm{mM} \mathrm{H}_{2} \mathrm{O}_{2}$ (66 and $80 \%$, respectively). This indicates that Cys47 is very sensitive for oxidation. The other $\mathrm{Zn}^{2+}$-coordinating cysteine Cys 177 also showed increased reversible oxidation up to $55 \%$ after $5 \mathrm{mM} \mathrm{H}_{2} \mathrm{O}_{2}$ treatment. Interestingly, Cys271, which is located in the $\mathrm{NAD}^{+}$cofactorbinding site, was mainly found in its reduced form independent of the treatment. To analyze the importance of these three cysteines, we have generated GSNOR mutants, where these cysteine residues were exchanged by serine resulting GSNOR ${ }^{\mathrm{C} 47 \mathrm{~S}}$, GSNOR $^{\mathrm{C} 177 \mathrm{~S}}$, and GSNOR ${ }^{\mathrm{C} 271 \mathrm{~S}}$. GSNOR ${ }^{\mathrm{C} 47 \mathrm{~S}}$ and GSNOR ${ }^{\mathrm{C} 177 \mathrm{~S}}$ showed drastically reduced specific activity (100-fold less and 50fold less, respectively) compared to WT GSNOR (Figure 6D) demonstrating the importance of these two cysteines. In contrast, the mutation of Cys 271 resulted in twofold increase of the specific activity.

\section{$\mathrm{H}_{2} \mathrm{O}_{2}$-Induced $\mathrm{Zn}^{2+}$ Release of GSNOR}

$S$-nitrosoglutathione-reductase contains two $\mathrm{Zn}^{2+}$ per subunit; one is located in the active center of protein called catalytic 
A

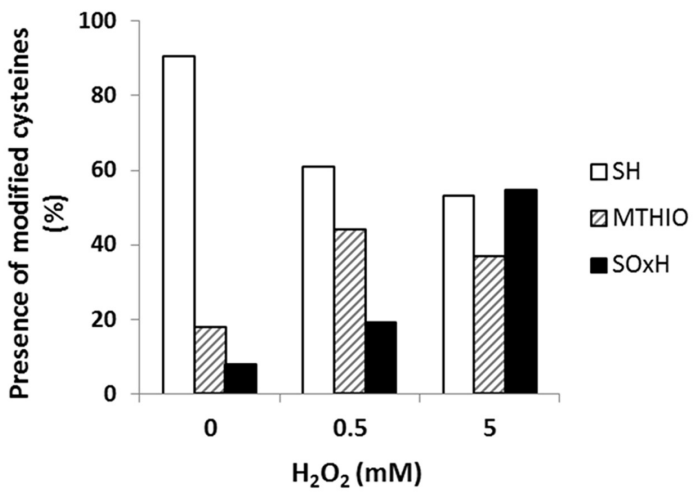

B

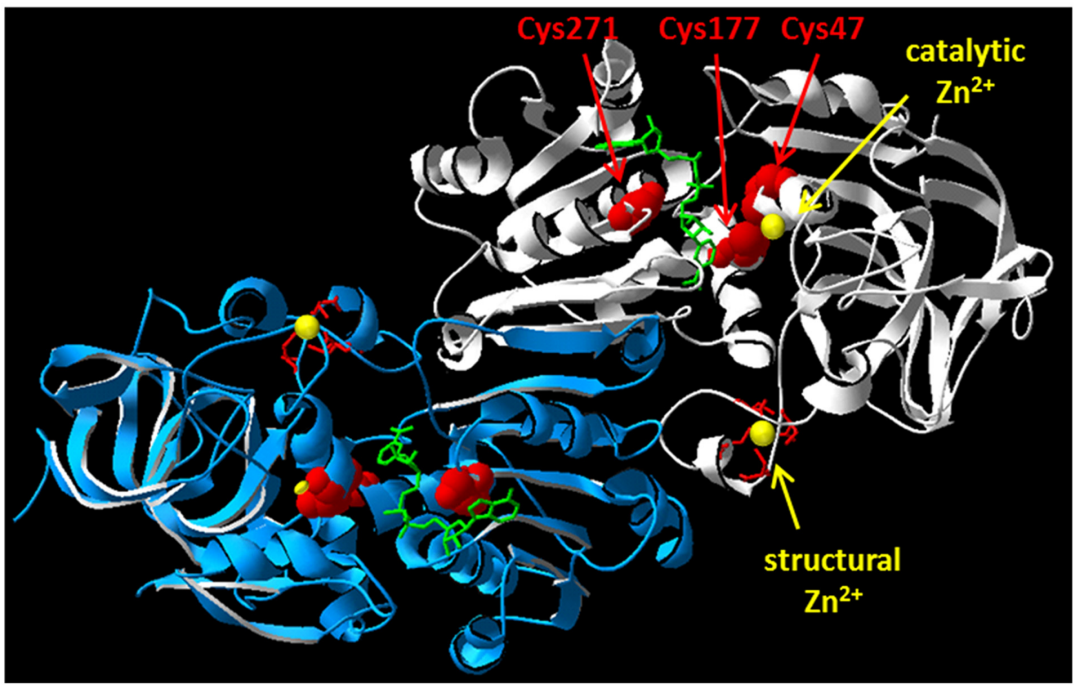

C

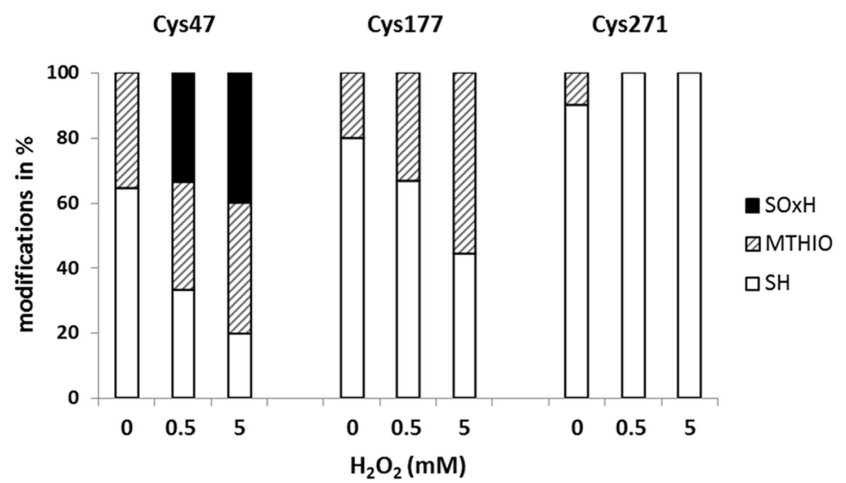

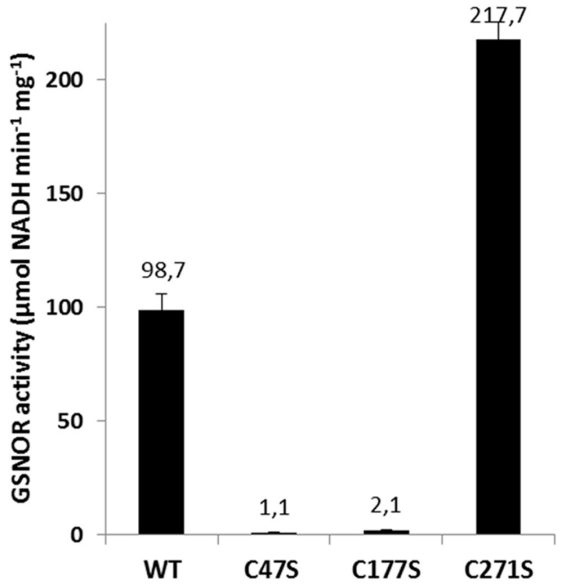

FIGURE 6 | Oxidative modifications of multiple cysteine residues of GSNOR correlate to reduced activity. (A) nano LC-MS/MS analysis of cysteine residues of recombinant GSNOR oxidized with 0.5 and $5 \mathrm{mM} \mathrm{H}_{2} \mathrm{O}_{2}$. The portion of different modification is represented as the mean percentage of all detected peptides (modifications of individual cysteines are shown in Supplementary Figure S1). SH represents free cysteines, MTHIO-labeling shows reversibly modifications, and SOxH represents irreversibly oxidative modifications. (B) Percentage distribution of different modifications (SH, MTHIO, and SOxH) of Cys47, Cys177, and Cys271 residues of oxidized GSNOR by nano LC-MS/MS. (C) 3D structure of Arabidopsis GSNOR (PDB code: 3UKO) as a homodimer (two subunit is labeled by white and blue). Cysteine residues in the substrate-binding site are highlighted in red. The bound NAD+ cofactor is shown by green sticks. The catalytic and structural $\mathrm{Zn}^{2+}$ is labeled by yellow. (D) Specific enzyme activity was determined of WT GSNOR and cysteine mutants GSNORC47S, GSNOR ${ }^{\mathrm{C} 177 \mathrm{~S}}$, and GSNOR $^{\mathrm{C} 271 \mathrm{~S}}$. The mean values with SD of three determinations are presented in the graph. 


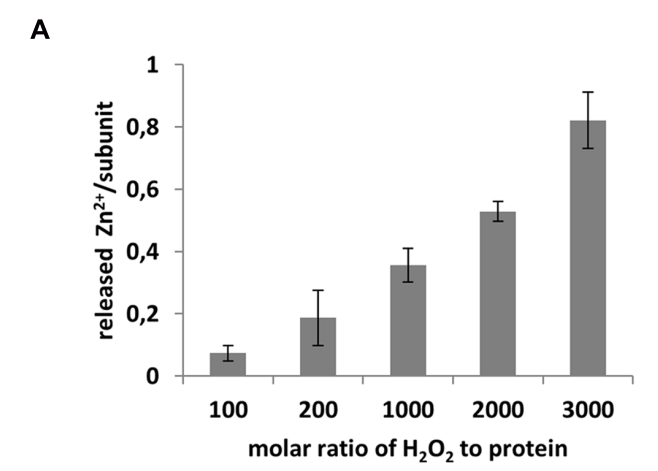

B

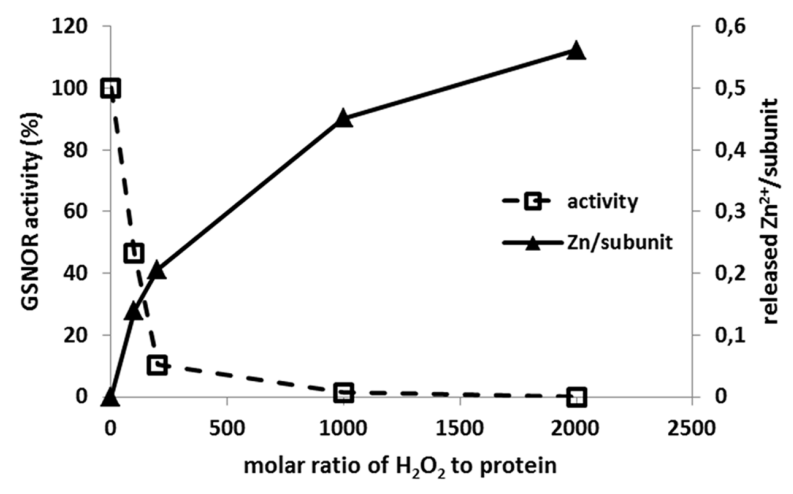

FIGURE $7 \mid \mathrm{H}_{2} \mathrm{O}_{2}$-induced $\mathrm{Zn}^{2+}$ release of GSNOR protein. (A) Determination of $\mathrm{Zn}^{2+}$ release of recombinant GSNOR (50-100 $\left.\mu \mathrm{g}\right)$ incubated for $1 \mathrm{~h}$ with increasing molar excess of $\mathrm{H}_{2} \mathrm{O}_{2}$ as indicated. The measured $\mathrm{Zn}^{2+}$ was first corrected by untreated GSNOR sample

(background correction) and then calculated to one subunit of GSNOR. (B) Representative experiment for parallel measurement of GSNOR activity and $\mathrm{Zn}^{2+}$ release using the same oxidized sample as indicated. GSNOR activity is presented as percentage of untreated protein. The released $\mathrm{Zn}^{2+}$ is calculated to one subunit of GSNOR.

$\mathrm{Zn}^{2+}$, the other one is structural $\mathrm{Zn}^{2+}$. The catalytic $\mathrm{Zn}^{2+}$ is coordinated by Cys47 and Cys177 and both are sensitive for oxidation (Figure 6C). Therefore, we tested whether oxidative inhibition of enzyme correlates with $\mathrm{Zn}^{2+}$-release. Treatment of recombinant GSNOR protein with $\mathrm{H}_{2} \mathrm{O}_{2}$ resulted in $\mathrm{Zn}^{2+}$. release in a $\mathrm{H}_{2} \mathrm{O}_{2}$ concentration-dependent manner (Figure 7A). We observed a maximum release of $0.82 \mathrm{Zn}^{2+}( \pm 0.16)$ calculated for one subunit of the dimer with the highest molar excess of $\mathrm{H}_{2} \mathrm{O}_{2}$ (3000-fold excess corresponded to $20 \mathrm{mM} \mathrm{H} \mathrm{H}_{2} \mathrm{O}_{2}$ ). The activity measurement of the $\mathrm{H}_{2} \mathrm{O}_{2}$-treated GSNOR showed that the enzyme was completely inhibited by 1000 -fold molar excess of $\mathrm{H}_{2} \mathrm{O}_{2}$ (Figure 7B). This corresponds to a release of $0.4 \mathrm{Zn}^{2+} /$ subunit (Figure 7B) suggesting a correlation between activity loss and $\mathrm{Zn}^{2+}$-release. We could not measure higher $\mathrm{Zn}^{2+}$-release than $0.98 \mathrm{Zn}^{2+}$ /subunit indicating that the second $\mathrm{Zn}^{2+}$ atom (the structural one) is probably not affected by oxidation. Interestingly, excess of external $\mathrm{Zn}^{2+}$ prevented $\mathrm{H}_{2} \mathrm{O}_{2}$-caused inhibition of GSNOR activity (Supplementary Figure S6), further confirming, that loss of $\mathrm{Zn}^{2+}$ results in loss of GSNOR activity.

\section{DISCUSSION}

The term oxidative stress describes the temporary imbalance of the cellular redox homeostasis due to enhanced accumulation of ROS triggering both signaling events and damaging processes (Foyer and Noctor, 2013). A change in ROS homeostasis and the associated shift in the redox state are induced primarily by external environmental influences during various abiotic and biotic stress treatments summarized in Mittler (2002). The major posttranslational protein modifications arising from interaction with ROS are oxidation of sulfur-containing residues (cysteine, methionine) and aromatic residues (tyrosine, tryptophan), carbonylation reactions and formation of disulfide bridges (Rinalducci et al., 2008; Waszczak et al., 2015). Besides ROS, reactive nitrogen species are very important signaling molecules in plants involved in biotic and abiotic stress responses. GSNOR activity controls intracellular levels of GSNO and S-nitrosylated proteins and the physiological importance of GSNOR in finetuning $\mathrm{NO} / \mathrm{SNO}$ levels during many stress responses and in plant growth and development is well described. To investigate the effect of oxidative modifications on individual proteins is crucial in understanding the signaling responses under different stress conditions. We demonstrate that GSNOR activity is inhibited by $\mathrm{H}_{2} \mathrm{O}_{2}$ in vitro or paraquat in vivo (Figures $1 \mathbf{A}$ and $4 \mathbf{A}$ ), providing a new evidence for crosstalk between ROS and NO signaling. $\mathrm{H}_{2} \mathrm{O}_{2}$-dependent inhibition of GSNOR activity was also observed in Baccaurea ramiflora (Burmese grape) investigating chilling stress (Bai et al., 2012). Moreover, alcohol dehydrogenase 1 (YADH1) from Saccharomyces cerevisiae was also inhibited by $\mathrm{H}_{2} \mathrm{O}_{2}$ in vitro due to oxidative modifications of specific cysteine residues (Men and Wang, 2007). This enzyme is structurally related to GSNOR (class III alcohol dehydrogenase). After $\mathrm{H}_{2} \mathrm{O}_{2}$ treatment, Cys43 and Cys153 of YADH1 were oxidized and three disulfide bonds (Cys43-Cys153, Cys103-Cys111, Cys276Cys277) were detected (Men and Wang, 2007). Cys43 and Cys153 of YADH1 correspond to Arabidopsis GSNOR Cys47 and Cys177 and they are conserved residues in class III alcohol dehydrogenases coordinating the catalytic $\mathrm{Zn}^{2+}$. In correlation with YADH1, we also observed oxidative modifications of these two residues (reversible and/or $\mathrm{SO}_{2} \mathrm{H}$ and $\mathrm{SO}_{3} \mathrm{H}$ ) by MS analyses of $\mathrm{H}_{2} \mathrm{O}_{2}$-treated Arabidopsis GSNOR (Figure 6). Moreover, our results show that nearly all detected cysteine residues were accessible to oxidative modification in a dosedependent manner (Supplementary Figure S5). In contrast to YADH1, we could not detect a disulphide formation of Arabidopsis GSNOR by a shift on non-reducing SDS-PAGE (Supplementary Figure S4) and also not by MS (data not shown). Substitution of Cys47 and Cys177 to serine residues resulted in a loss of GSNOR activity (Figure 6D) indicating the importance of a $\mathrm{Zn}^{2+}$-thiolate catalytic center. Early biochemical studies in mammals showed evidence that oxidation of cysteines of zinc-finger transcription factors can abolish DNA binding and transcriptional functions (Webster et al., 2001). Superoxideinduced $\mathrm{Zn}^{2+}$ release has also been demonstrated in the zinc finger motif of protein kinase C (Knapp and Klann, 2000). Furthermore, investigation of different oxidants on the oxidative $\mathrm{Zn}^{2+}$ release in YADH1 revealed an inverse correlation between 
alcohol dehydrogenase activity and the released $\mathrm{Zn}^{2+}$ (Daiber et al., 2002). The strongest oxidant was peroxynitrite leading to release of one zinc atom/subunit of YADH1, following $\mathrm{H}_{2} \mathrm{O}_{2}$ and the less effective was NO. Oxidation of recombinant Arabidopsis GSNOR by $\mathrm{H}_{2} \mathrm{O}_{2}$ also resulted in a $\mathrm{Zn}^{2+}$ release (Figure 7). Similarly, Arabidopsis GSNOR contains two $\mathrm{Zn}^{2+}$ per subunit, however, we observed the release of only one $\mathrm{Zn}^{2+}$ /subunit at the highest excess of $\mathrm{H}_{2} \mathrm{O}_{2}$ (at molar excess of 3000). Since the $\mathrm{Zn}^{2+}$-release has been accompanied by loss of activity we assumed that most likely $\mathrm{Zn}^{2+}$ from the active center of the protein is released. Moreover, Cys47, which is involved in coordinating the catalytic $\mathrm{Zn}^{2+}$, is very sensitive to oxidation (Figure $6 \mathrm{C}$ ). The second $\mathrm{Zn}^{2+}$ (structural $\mathrm{Zn}^{2+}$ ) is coordinated by four cysteine residues (Cys94, Cys99, Cys102, and Cys105) and is not involved in the enzymatic activity of GSNOR. Interestingly, S-nitrosation of conserved non-zinc coordinating cysteines (Cys10, Cys271, and Cys370) were reported very recently and this modification was shown to cause a catalytic inhibition of Arabidopsis GSNOR (Guerra et al., 2016).

To analyze the ROS-induced inhibition of Arabidopsis GSNOR in vivo, the bipyridium herbicide paraquat was used as a ROS-inducing agent (Vaughn and Duke, 1983). The redox cycling of paraquat with molecular oxygen produces superoxide radical, which is then mainly dismutated by superoxide dismutase (SOD) to $\mathrm{H}_{2} \mathrm{O}_{2}$ (Bus and Gibson, 1984). However, in the presence of $\mathrm{NO}$, peroxynitrite is formed from the reaction between $\mathrm{O}_{2}{ }^{-}$and $\mathrm{NO}$, which is approximately six-times faster than the dismutation by SOD (Pacher et al., 2007). $\mathrm{ONOO}^{-}$is a powerful oxidant and nitrosating compound in the cellular environment modifying amino acids, nucleic acids, low and high molecular weight thiols and phospholipids. Paraquat reversibly inhibits GSNOR activity (Figure 1A) resulting in enhanced levels of SNOs (Figure 2A). Plants that lack GSNOR activity are more tolerant toward paraquat than WT plants, which develop cell death phenotype germinated on $0.5-1 \mu \mathrm{M}$ paraquatcontaining media (Figures 1C,D) (Chen et al., 2009) suggesting an activated resistance mechanisms in gsnor plants. Enhanced levels of cellular SNOs in gsnor in comparison to WT plants (Figure 2A) might be responsible for the observed tolerance against paraquat-induced oxidative stress. In correlation, SNO levels increased more than twofold in WT plants after paraquat treatment (Figure 2A) providing evidence for ROS-induced inactivation of GSNOR in vivo. Co-treatment of NO donor sodium nitroprusside and paraquat during germination of WT plants resulted in increased resistance to paraquat supports this hypothesis (Chen et al., 2009). A protective effect of NO against paraquat-induced oxidative stress was also described in potato and rice after incubation with NO-releasing compounds, however, the exact mechanism is not provided (Beligni and Lamattina, 1999; Hung et al., 2002). Normally, higher SNO/NO levels in gsnor plants should increase the production of $\mathrm{ONOO}^{-}$ during paraquat treatment. In contrast, we observed a reduced tyrosine nitration level as a marker for $\mathrm{ONOO}^{-}$production in the paraquat-treated gsnor plant (Supplementary Figure S1B). This result indicates that either the production or the turnover of $\mathrm{ONOO}^{-}$is affected by excess $\mathrm{NO} / \mathrm{SNO}$. It was demonstrated in soybean cells that $\mathrm{ONOO}^{-}$is not a determining factor of hypersensitive cell death, but the common action of NO and $\mathrm{H}_{2} \mathrm{O}_{2}$ (Delledonne et al., 2001). The paraquat-treated gsnor mutant accumulates lower amount of $\mathrm{H}_{2} \mathrm{O}_{2}$ than the WT plant (Supplementary Figure S3) supporting the scavenging function of NO to decrease excess level of ROS species. On one side, peroxynitrite formation can be a mechanism to consume superoxide thereby protecting biomolecules from oxidation and preventing further ROS production (Kanner et al., 1991; Wink et al., 2003). On the other side, $\mathrm{ONOO}^{-}$can inhibit several isoforms of SOD (Holzmeister et al., 2015) resulting in less $\mathrm{H}_{2} \mathrm{O}_{2}$ production. Besides the scavenging function of NO, the plant cell can overcome elevated ROS levels by activating the antioxidant system. GSH is one of the major low molecular weight thiol, which reacts rapidly to changing stress situations and is crucial to maintain cellular redox balance. Both, loss of GSNOR function and fumigation with NO enhanced GSH level (Figures 3A,C) assuming that $\mathrm{NO} / \mathrm{SNO}$ is able to stimulate the GSH biosynthesis pathway. These measurements coincide with previous reports demonstrating a higher amount of GSH in roots of Medicago truncatula (Innocenti et al., 2007) and maize leaves (Mello et al., 2012) after GSNO and SNP treatment, respectively. In both cases, an enhanced expression of the $\gamma$-glutamylcysteine synthetase and GSH synthetase gene was detectable suggesting a NO-dependent transcriptional regulation of GSH production. Together with a twofold higher glutathione content in gsnor plants, we measured increased glutathione reductase activity (Figure 3B), which is responsible for the recovery of GSH and thus the maintenance of the redox homeostasis. Assuming that the GR activity is involved in GSH regeneration, the gsnor plants would therefore be able to provide more reducing equivalents needed for the stress response (Figure 3A). Moreover, increased conjugase activity of GST was measured in gsnor plants with and without paraquat treatment (Figure 3B). Enhanced GST activity could be observed in response to different abiotic and biotic stimuli and their activity is important to protect plants against oxidative damage (Sappl et al., 2009). The induction of the antioxidant system in gsnor plants was further demonstrated by a transcript profile analysis. Comparison of WT and gsnor plants under normal growth condition revealed an enhanced expression of genes involved in antioxidant processes in gsnor plants (Table 1). The up-regulated genes of peroxidases or GSTs are markers for oxidative stress and/or $\mathrm{H}_{2} \mathrm{O}_{2}$ signaling (Vanderauwera et al., 2005; Queval et al., 2012). However, little is known about the exact physiological function of these enzymes during oxidative stress. Interestingly, several members of the Tau class GSTs are also upregulated during paraquat and $\mathrm{H}_{2} \mathrm{O}_{2}$ treatment of Arabidopsis seedlings (Genevestigator At-413 and Genevestigator At-185). Moreover, using a yeast two-hybrid approach a tomato cDNA library was screened for "proteins" protecting yeast from prooxidant-induced cell death. In this screen five homologous Tau class GSTs were identified concluding that especially this class of GST proteins has a protective function in oxidative stress response (Kilili et al., 2004). The fact that the expression of 13 members of the Tau subfamily of GSTs is upregulated in 
gsnor plants in comparison to WT plants suggests that these genes are regulated by $\mathrm{SNO} / \mathrm{NO}$ and are important for protection against oxidative stress. Although peroxisomal catalases and the ascorbate-glutathione pathway play a primarily role in the metabolism of $\mathrm{H}_{2} \mathrm{O}_{2}$ (Mhamdi et al., 2010; Noctor et al., 2012), we did not observed any changes in the expression of catalases or genes related to the ascorbate-glutathione-dependent pathway like APX or dehydroascorbate reductases. However, several other classes of antioxidative peroxidases exist that can reduce $\mathrm{H}_{2} \mathrm{O}_{2}$ and/or organic peroxides. These include thioredoxin-, or glutathione-peroxidases, and glutathione-S-transferases (Dietz, 2003; Dixon et al., 2009). Based on our microarray data an alternative pathway involving SNO/NO-induced thioredoxinand/or glutathione-dependent peroxidases might be present and result in activation of the antioxidative system.

Furthermore, a thiol protective role of $S$-nitrosylation has been reported in animals (Evangelista et al., 2013). Formation of higher order irreversible oxidative modifications, such as sulfinic and sulfonic acids were prevented by $S$-nitrosylation. Recent paper has provided evidence that $S$-nitrosylation of Arabidopsis APX1 enhances its activity to scavenge $\mathrm{H}_{2} \mathrm{O}_{2}$ and to increase resistance to oxidative stress (Yang et al., 2015). S-Nitrosylation of pea APX also enhanced its enzyme activity in saline stress (Begara-Morales et al., 2014). Moreover, the activity of NADPH oxidase is inhibited by $S$-nitrosylation, resulting in the reduction in ROS biosynthesis during immune responses (Yun et al., 2011). Interestingly, activity of Arabidopsis GSNOR is inhibited by $S$-nitrosylation demonstrating that SNOs control its own scavenging by modulating GSNOR activity (Frungillo et al., 2014; Guerra et al., 2016).

In sum, we demonstrated that GSNOR activity can be inhibited in vitro by $\mathrm{H}_{2} \mathrm{O}_{2}$, as well as in vivo by paraquat, which is accompanied by a significant change in NO homeostasis. The observed increase in cellular SNOs consequently leads to induction of NO-dependent signaling mechanisms, resulting in GSH accumulation, enhanced activity of GSH-related enzymes

\section{REFERENCES}

Apel, K., and Hirt, H. (2004). Reactive oxygen species: metabolism, oxidative stress, and signal transduction. Annu. Rev. Plant Biol. 55, 373-399. doi: 10.1146/annurev.arplant.55.031903.141701

Arasimowicz-Jelonek, M., and Floryszak-Wieczorek, J. (2011). Understanding the fate of peroxynitrite in plant cells-from physiology to pathophysiology. Phytochemistry 72, 681-688. doi: 10.1016/j.phytochem.2011.02.025

Astier, J., and Lindermayr, C. (2012). Nitric oxide-dependent posttranslational modification in plants: an update. Int. J. Mol. Sci. 13, 15193-15208. doi: 10.3390/ijms131115193

Babbs, C. F., Pham, J. A., and Coolbaugh, R. C. (1989). Lethal hydroxyl radical production in paraquat-treated plants. Plant Physiol. 90, 1267-1270. doi: 10.1104/pp.90.4.1267

Bai, X. G., Chen, J. H., Kong, X. X., Todd, C. D., Yang, Y. P., Hu, X. Y., et al. (2012). Carbon monoxide enhances the chilling tolerance of recalcitrant Baccaurea ramiflora seeds via nitric oxide-mediated glutathione homeostasis. Free Radic. Biol. Med. 53, 710-720. doi: 10.1016/j.freeradbiomed.2012. 05.042

Begara-Morales, J. C., Sanchez-Calvo, B., Chaki, M., Valderrama, R., MataPerez, C., Lopez-Jaramillo, J., et al. (2014). Dual regulation of cytosolic ascorbate peroxidase (APX) by tyrosine nitration and S-nitrosylation. J. Exp. Bot. 65, 527-538. doi: 10.1093/jxb/ert396 and finally in a protection against oxidative stress. All these findings substantiate the physiological importance of GSNOR in fine-tuning the levels of $\mathrm{NO} / \mathrm{SNO}$ during plant growth and development and also in many stress response reactions.

\section{AUTHOR CONTRIBUTIONS}

IK, CH, and CL designed research. IK, CH, MW, AG, GR, TF, GK, and EL performed research. IK, CH, MW, AG, TF, RH, GA, $\mathrm{JD}$, and $\mathrm{CL}$ analyzed data. IK, CH, and CL wrote the paper.

\section{FUNDING}

This work was supported by the Bundesministerium für Bildung und Forschung and by grants ZUK 49/2, SFB 1036-TP13, HE1848/16-1 and WI3560/2-1 from the Deutsche Forschungsgemeinschaft.

\section{ACKNOWLEDGMENTS}

We thank Elke Mattes, Lucia Gößl, and Rosina Ludwig for excellent technical assistance and Elisabeth Georgii for help in the statistical analysis. We also thank Elizabeth Vierling and Damian Guerra for fruitful discussion. We thank the Metabolomics Core Technology Platform of the Excellence Cluster CellNetworks for support with HPLC-based metabolite quantification.

\section{SUPPLEMENTARY MATERIAL}

The Supplementary Material for this article can be found online at: http://journal.frontiersin.org/article/10.3389/fpls.2016.01669/ full\#supplementary-material

Beligni, M. V., and Lamattina, L. (1999). Nitric oxide counteracts cytotoxic processes mediated by reactive oxygen species in plant tissues. Planta 208, 337-344. doi: 10.1007/s004250050567

Benezra, R. (1994). An intermolecular disulfide bond stabilizes E2A homodimers and is required for DNA binding at physiological temperatures. Cell 79, 10571067. doi: 10.1016/0092-8674(94)90036-1

Bus, J. S., and Gibson, J. E. (1984). Paraquat: model for oxidant-initiated toxicity. Environ. Health Perspect. 55, 37-46. doi: 10.1289/ehp.845537

Chen, R., Sun, S., Wang, C., Li, Y., Liang, Y., An, F., et al. (2009). The Arabidopsis PARAQUAT RESISTANT2 gene encodes an S-nitrosoglutathione reductase that is a key regulator of cell death. Cell Res. 19, 1377-1387. doi: 10.1038/cr.2009.117

Corpas, F. J., Alche, J. D., and Barroso, J. B. (2013). Current overview of S-nitrosoglutathione (GSNO) in higher plants. Front. Plant Sci. 4:126. doi: 10.3389/fpls.2013.00126

Corpas, F. J., Leterrier, M., Valderrama, R., Airaki, M., Chaki, M., Palma, J. M., et al. (2011). Nitric oxide imbalance provokes a nitrosative response in plants under abiotic stress. Plant Sci. 181, 604-611. doi: 10.1016/j.plantsci.2011.04.005

Crow, J. P., Sampson, J. B., Zhuang, Y., Thompson, J. A., and Beckman, J. S. (1997). Decreased zinc affinity of amyotrophic lateral sclerosis-associated superoxide dismutase mutants leads to enhanced catalysis of tyrosine nitration by peroxynitrite. J. Neurochem. 69, 1936-1944. doi: 10.1046/j.14714159.1997.69051936.x 
Daiber, A., Frein, D., Namgaladze, D., and Ullrich, V. (2002). Oxidation and nitrosation in the nitrogen monoxide/superoxide system. J. Biol. Chem. 277, 11882-11888. doi: 10.1074/jbc.M111988200

Delledonne, M., Zeier, J., Marocco, A., and Lamb, C. (2001). Signal interactions between nitric oxide and reactive oxygen intermediates in the plant hypersensitive disease resistance response. Proc. Natl. Acad. Sci. U.S.A. 98, 13454-13459. doi: 10.1073/pnas.231178298

Despres, C., Chubak, C., Rochon, A., Clark, R., Bethune, T., Desveaux, D., et al. (2003). The Arabidopsis NPR1 disease resistance protein is a novel cofactor that confers redox regulation of DNA binding activity to the basic domain/leucine zipper transcription factor TGA1. Plant Cell 15, 2181-2191. doi: $10.1105 /$ tpc.012849

Dietz, K. J. (2003). Plant peroxiredoxins. Annu. Rev. Plant Biol. 54, 93-107. doi: 10.1146/annurev.arplant.54.031902.134934

Dietz, K. J. (2014). Redox regulation of transcription factors in plant stress acclimation and development. Antioxid. Redox. Signal. 21, 1356-1372. doi: 10.1089/ars.2013.5672

Dixon, D. P., Hawkins, T., Hussey, P. J., and Edwards, R. (2009). Enzyme activities and subcellular localization of members of the Arabidopsis glutathione transferase superfamily. J. Exp. Bot. 60, 1207-1218. doi: 10.1093/jxb/ ern365

Dodge, A. D. (1971). The mode of action of the bipyridylium herbicides, paraquat and diquat. Endeavour 30, 130-135. doi: 10.1016/0160-9327(71)90039-1

Doke, N. (1983). Involvement of superoxide anion generation in the hypersensitive response of potato tuber tissues to infection with an incompatible race of Phytophthora infestans and to the hyphal wall components. Physiol. Plant Pathol. 23, 345-357. doi: 10.1016/0048-4059(83)90020-6

Espunya, M. C., De Michele, R., Gomez-Cadenas, A., and Martinez, M. C. (2012). S-Nitrosoglutathione is a component of wound- and salicylic acid-induced systemic responses in Arabidopsis thaliana. J. Exp. Bot. 63, 3219-3227. doi: 10.1093/jxb/ers043

Evangelista, A. M., Kohr, M. J., and Murphy, E. (2013). S-nitrosylation: specificity, occupancy, and interaction with other post-translational modifications. Antioxid. Redox. Signal. 19, 1209-1219. doi: 10.1089/ars.2012. 5056

Feechan, A., Kwon, E., Yun, B. W., Wang, Y., Pallas, J. A., and Loake, G. J. (2005). A central role for S-nitrosothiols in plant disease resistance. Proc. Natl. Acad. Sci. U.S.A. 102, 8054-8059. doi: 10.1073/pnas.0501456102

Foyer, C. H., and Noctor, G. (2013). Redox signaling in plants. Antioxid. Redox. Signal. 18, 2087-2090. doi: 10.1089/ars.2013.5278

Frungillo, L., Skelly, M. J., Loake, G. J., Spoel, S. H., and Salgado, I. (2014). S-nitrosothiols regulate nitric oxide production and storage in plants through the nitrogen assimilation pathway. Nat. Commun. 5:5401. doi: 10.1038/ncomms6401

Guerra, D., Ballard, K., Truebridge, I., and Vierling, E. (2016). S-nitrosation of conserved cysteines modulates activity and stability of S-nitrosoglutathione reductase (GSNOR). Biochemistry 55, 2452-2464. doi: 10.1021/acs.biochem.5b01373

Gupta, R., and Luan, S. (2003). Redox control of protein tyrosine phosphatases and mitogen-activated protein kinases in plants. Plant Physiol. 132, 1149-1152. doi: 10.1104/pp.103.020792

Holzmeister, C., Gaupels, F., Geerlof, A., Sarioglu, H., Sattler, M., Durner, J., et al. (2015). Differential inhibition of Arabidopsis superoxide dismutases by peroxynitrite-mediated tyrosine nitration. J. Exp. Bot. 66, 989-999. doi: 10.1093/jxb/eru458

Hung, K. T., Chang, C. J., and Kao, C. H. (2002). Paraquat toxicity is reduced by nitric oxide in rice leaves. J. Plant Physiol. 159, 159-166. doi: 10.1078/01761617-00692

Innocenti, G., Pucciariello, C., Le Gleuher, M., Hopkins, J., De Stefano, M., Delledonne, M., et al. (2007). Glutathione synthesis is regulated by nitric oxide in Medicago truncatula roots. Planta 225, 1597-1602. doi: 10.1007/s00425-0060461-3

Jammes, F., Song, C., Shin, D., Munemasa, S., Takeda, K., Gu, D., et al. (2009). MAP kinases MPK9 and MPK12 are preferentially expressed in guard cells and positively regulate ROS-mediated ABA signaling. Proc. Natl. Acad. Sci. U.S.A. 106, 20520-20525. doi: 10.1073/pnas.0907205106

Kanner, J., Harel, S., and Granit, R. (1991). Nitric oxide as an antioxidant. Arch. Biochem. Biophys. 289, 130-136. doi: 10.1016/0003-9861(91)90452-O
Katari, M. S., Nowicki, S. D., Aceituno, F. F., Nero, D., Kelfer, J., Thompson, L. P., et al. (2010). VirtualPlant: a software platform to support systems biology research. Plant Physiol. 152, 500-515. doi: 10.1104/pp.109.147025

Kilili, K. G., Atanassova, N., Vardanyan, A., Clatot, N., Al-Sabarna, K., Kanellopoulos, P. N., et al. (2004). Differential roles of tau class glutathione S-transferases in oxidative stress. J. Biol. Chem. 279, 24540-24551. doi: 10.1074/jbc.M309882200

Knapp, L. T., and Klann, E. (2000). Superoxide-induced stimulation of protein kinase $\mathrm{C}$ via thiol modification and modulation of zinc content. J. Biol. Chem. 275, 24136-24145. doi: 10.1074/jbc.M002043200

Konig, J., Muthuramalingam, M., and Dietz, K. J. (2012). Mechanisms and dynamics in the thiol/disulfide redox regulatory network: transmitters, sensors and targets. Curr. Opin. Plant Biol. 15, 261-268. doi: 10.1016/j.pbi.2011.12.002

Kovacs, I., and Lindermayr, C. (2013). Nitric oxide-based protein modification: formation and site-specificity of protein S-nitrosylation. Front. Plant Sci. 4:137. doi: 10.3389/fpls.2013.00137

Kubienova, L., Kopecny, D., Tylichova, M., Briozzo, P., Skopalova, J., Sebela, M., et al. (2013). Structural and functional characterization of a plant S-nitrosoglutathione reductase from Solanum lycopersicum. Biochimie 95, 889-902. doi: 10.1016/j.biochi.2012.12.009

Kulik, A., Noirot, E., Grandperret, V., Bourque, S., Fromentin, J., Salloignon, P., et al. (2014). Interplays between nitric oxide and reactive oxygen species in cryptogein signalling. Plant Cell Environ. 38, 331-348. doi: 10.1111/pce.12295

Kwon, E., Feechan, A., Yun, B. W., Hwang, B. H., Pallas, J. A., Kang, J. G., et al. (2012). AtGSNOR1 function is required for multiple developmental programs in Arabidopsis. Planta 236, 887-900. doi: 10.1007/s00425-012-1697-8

Lee, U., Wie, C., Fernandez, B. O., Feelisch, M., and Vierling, E. (2008). Modulation of nitrosative stress by S-nitrosoglutathione reductase is critical for thermotolerance and plant growth in Arabidopsis. Plant Cell 20, 786-802. doi: 10.1105/tpc.107.052647

Lindermayr, C., Fliegmann, J., and Ebel, J. (2003). Deletion of a single amino acid residue from different 4-coumarate:CoA ligases from soybean results in the generation of new substrate specificities. J. Biol. Chem. 278, 2781-2786. doi: 10.1074/jbc.M202632200

Lindermayr, C., Sell, S., Muller, B., Leister, D., and Durner, J. (2010). Redox regulation of the NPR1-TGA1 system of Arabidopsis thaliana by nitric oxide. Plant Cell 22, 2894-2907. doi: 10.1105/tpc.109.066464

Liu, L., Hausladen, A., Zeng, M., Que, L., Heitman, J., and Stamler, J. S. (2001). A metabolic enzyme for S-nitrosothiol conserved from bacteria to humans. Nature 410, 490-494. doi: 10.1038/35054017

Mahoney, C. W., Pak, J. H., and Huang, K. P. (1996). Nitric oxide modification of rat brain neurogranin. Identification of the cysteine residues involved in intramolecular disulfide bridge formation using site-directed mutagenesis. J. Biol. Chem. 271, 28798-28804. doi: 10.1074/jbc.271.46.28798

Martinez, M. C., Achkor, H., Persson, B., Fernandez, M. R., Shafqat, J., Farres, J., et al. (1996). Arabidopsis formaldehyde dehydrogenase. Molecular properties of plant class III alcohol dehydrogenase provide further insights into the origins, structure and function of plant class $\mathrm{p}$ and liver class I alcohol dehydrogenases. Eur. J. Biochem. 241, 849-857. doi: 10.1111/j.1432-1033.1996.00849.x

Mello, C. S., Hermes, V. S., Guerra, M. P., and Arisi, A. C. M. (2012). Sodium nitroprusside modulates gene expression involved in glutathione synthesis in Zea mays leaves. Biol. Plant. 56, 383-388. doi: 10.1007/s10535-012-0104-4

Men, L., and Wang, Y. (2007). The oxidation of yeast alcohol dehydrogenase-1 by hydrogen peroxide in vitro. J. Proteome Res. 6, 216-225. doi: 10.1021/pr0603809

Mhamdi, A., Queval, G., Chaouch, S., Vanderauwera, S., Van Breusegem, F., and Noctor, G. (2010). Catalase function in plants: a focus on Arabidopsis mutants as stress-mimic models. J. Exp. Bot. 61, 4197-4220. doi: 10.1093/jxb/erq282

Mittler, R. (2002). Oxidative stress, antioxidants and stress tolerance. Trends Plant Sci. 7, 405-410. doi: 10.1016/S1360-1385(02)02312-9

Noctor, G., Mhamdi, A., Chaouch, S., Han, Y., Neukermans, J., Marquez-Garcia, B., et al. (2012). Glutathione in plants: an integrated overview. Plant Cell Environ. 35, 454-484. doi: 10.1111/j.1365-3040.2011.02400.x

Pacher, P., Beckman, J. S., and Liaudet, L. (2007). Nitric oxide and peroxynitrite in health and disease. Physiol. Rev. 87, 315-424. doi: 10.1152/physrev.00029.2006

Queval, G., Neukermans, J., Vanderauwera, S., Van Breusegem, F., and Noctor, G. (2012). Day length is a key regulator of transcriptomic responses to both $\mathrm{CO}_{2}$ and $\mathrm{H}_{2} \mathrm{O}_{2}$ in Arabidopsis. Plant Cell Environ. 35, 374-387. doi: 10.1111/j.13653040.2011.02368.x 
Queval, G., and Noctor, G. (2007). A plate reader method for the measurement of NAD, NADP, glutathione, and ascorbate in tissue extracts: application to redox profiling during Arabidopsis rosette development. Anal. Biochem. 363, 58-69. doi: 10.1016/j.ab.2007.01.005

Rinalducci, S., Murgiano, L., and Zolla, L. (2008). Redox proteomics: basic principles and future perspectives for the detection of protein oxidation in plants. J. Exp. Bot. 59, 3781-3801. doi: 10.1093/jxb/ern252

Rusterucci, C., Espunya, M. C., Diaz, M., Chabannes, M., and Martinez, M. C. (2007). S-nitrosoglutathione reductase affords protection against pathogens in Arabidopsis, both locally and systemically. Plant Physiol. 143, 1282-1292. doi: 10.1104/pp.106.091686

Sakamoto, A., Ueda, M., and Morikawa, H. (2002). Arabidopsis glutathionedependent formaldehyde dehydrogenase is an S-nitrosoglutathione reductase. FEBS Lett. 515, 20-24. doi: 10.1016/S0014-5793(02)02414-6

Sanghani, P. C., Robinson, H., Bosron, W. F., and Hurley, T. D. (2002). Human glutathione-dependent formaldehyde dehydrogenase. Structures of apo, binary, and inhibitory ternary complexes. Biochemistry 41, 10778-10786. doi: $10.1021 /$ bi026705q

Sappl, P. G., Carroll, A. J., Clifton, R., Lister, R., Whelan, J., Harvey Millar, A., et al. (2009). The Arabidopsis glutathione transferase gene family displays complex stress regulation and co-silencing multiple genes results in altered metabolic sensitivity to oxidative stress. Plant J. 58, 53-68. doi: 10.1111/j.1365313X.2008.03761.x

Shaikhali, J., Noren, L., De Dios Barajas-Lopez, J., Srivastava, V., Konig, J., Sauer, U. H., et al. (2012). Redox-mediated mechanisms regulate DNA binding activity of the G-group of basic region leucine zipper (bZIP) transcription factors in Arabidopsis. J. Biol. Chem. 287, 27510-27525. doi: 10.1074/jbc.M112. 361394

Simontacchi, M., Galatro, A., Ramos-Artuso, F., and Santa-Maria, G. E. (2015). Plant survival in a changing environment: the role of nitric oxide in plant responses to abiotic stress. Front. Plant Sci. 6:977. doi: 10.3389/fpls.2015. 00977

Thordal-Christensen, H., Zhang, Z., Wei, Y., and Collinge, D. B. (1997). Subcellular localization of $\mathrm{H}_{2} \mathrm{O}_{2}$ in plants. $\mathrm{H}_{2} \mathrm{O}_{2}$ accumulation in papillae and hypersensitive response during the barley-powdery mildew interaction. Plant J. 11, 1187-1194. doi: 10.1046/j.1365-313X.1997.11061187.x

Vanderauwera, S., Zimmermann, P., Rombauts, S., Vandenabeele, S., Langebartels, C., Gruissem, W., et al. (2005). Genome-wide analysis of hydrogen peroxide-regulated gene expression in Arabidopsis reveals a high light-induced transcriptional cluster involved in anthocyanin biosynthesis. Plant Physiol. 139, 806-821. doi: 10.1104/pp.105.065896

Vaughn, K. C., and Duke, S. O. (1983). In situ localization of the sites of paraquat action. Plant Cell Environ. 6, 13-20. doi: 10.1111/1365-3040.ep11580509

Wang, C., El-Shetehy, M., Shine, M. B., Yu, K., Navarre, D., Wendehenne, D., et al. (2014). Free radicals mediate systemic acquired resistance. Cell Rep. 7, 348-355. doi: 10.1016/j.celrep.2014.03.032

Waszczak, C., Akter, S., Eeckhout, D., Persiau, G., Wahni, K., Bodra, N., et al. (2014). Sulfenome mining in Arabidopsis thaliana. Proc. Natl. Acad. Sci. U.S.A. 111, 11545-11550. doi: 10.1073/pnas.1411607111

Waszczak, C., Akter, S., Jacques, S., Huang, J., Messens, J., and Van Breusegem, F. (2015). Oxidative post-translational modifications of cysteine residues in plant signal transduction. J. Exp. Bot. 66, 2923-2934. doi: 10.1093/jxb/erv084
Webster, K. A., Prentice, H., and Bishopric, N. H. (2001). Oxidation of zinc finger transcription factors: physiological consequences. Antioxid. Redox. Signal. 3, 535-548. doi: 10.1089/15230860152542916

Wink, D. A., Miranda, K. M., Katori, T., Mancardi, D., Thomas, D. D., Ridnour, L., et al. (2003). Orthogonal properties of the redox siblings nitroxyl and nitric oxide in the cardiovascular system: a novel redox paradigm. Am. J. Physiol. Heart Circ. Physiol. 285, H2264-H2276. doi: 10.1152/ajpheart.00531.2003

Wirtz, M., Droux, M., and Hell, R. (2004). O-acetylserine (thiol) lyase: an enigmatic enzyme of plant cysteine biosynthesis revisited in Arabidopsis thaliana. J. Exp. Bot. 55, 1785-1798. doi: 10.1093/jxb/erh201

Xie, Y., Mao, Y., Zhang, W., Lai, D., Wang, Q., and Shen, W. (2014). Reactive Oxygen species-dependent nitric oxide production contributes to hydrogenpromoted stomatal closure in Arabidopsis. Plant Physiol. 165, 759-773. doi: 10.1104/pp.114.237925

Xu, S., Guerra, D., Lee, U., and Vierling, E. (2013). S-nitrosoglutathione reductases are low-copy number, cysteine-rich proteins in plants that control multiple developmental and defense responses in Arabidopsis. Front. Plant Sci. 4:430. doi: 10.3389/fpls.2013.00430

Yang, H., Mu, J., Chen, L., Feng, J., Hu, J., Li, L., et al. (2015). S-Nitrosylation positively regulates ascorbate peroxidase activity during plant stress responses. Plant Physiol. 167, 1604-1615. doi: 10.1104/pp.114.255216

Yao, L.-L., Pei, B.-L., Zhou, Q., and Li, Y.-Z. (2012). NO serves as a signaling intermediate downstream of $\mathrm{H}_{2} \mathrm{O}_{2}$ to modulate dynamic microtubule cytoskeleton during responses to VD-toxins in Arabidopsis. Plant Signal. Behav. 7, 174-177. doi: 10.4161/psb.18768

Yu, M., Lamattina, L., Spoel, S. H., and Loake, G. J. (2014). Nitric oxide function in plant biology: a redox cue in deconvolution. New Phytol. 202, 1142-1156. doi: 10.1111/nph.12739

Yun, B. W., Feechan, A., Yin, M., Saidi, N. B., Le Bihan, T., Yu, M., et al. (2011). $S$-nitrosylation of NADPH oxidase regulates cell death in plant immunity. Nature 478, 264-268. doi: 10.1038/nature10427

Zeida, A., Gonzalez Lebrero, M. C., Radi, R., Trujillo, M., and Estrin, D. A. (2013). Mechanism of cysteine oxidation by peroxynitrite: an integrated experimental and theoretical study. Arch. Biochem. Biophys. 539, 81-86. doi: 10.1016/j.abb.2013.08.016

Zhang, A., Jiang, M., Zhang, J., Ding, H., Xu, S., Hu, X., et al. (2007). Nitric oxide induced by hydrogen peroxide mediates abscisic acid-induced activation of the mitogen-activated protein kinase cascade involved in antioxidant defense in maize leaves. New Phytol. 175, 36-50. doi: 10.1111/j.1469-8137.2007.02071.x

Conflict of Interest Statement: The authors declare that the research was conducted in the absence of any commercial or financial relationships that could be construed as a potential conflict of interest.

Copyright (c) 2016 Kovacs, Holzmeister, Wirtz, Geerlof, Fröhlich, Römling, Kuruthukulangarakoola, Linster, Hell, Arnold, Durner and Lindermayr. This is an open-access article distributed under the terms of the Creative Commons Attribution License (CC BY). The use, distribution or reproduction in other forums is permitted, provided the original author(s) or licensor are credited and that the original publication in this journal is cited, in accordance with accepted academic practice. No use, distribution or reproduction is permitted which does not comply with these terms. 